Revue

d'ethnoécologie
Revue d'ethnoécologie

12 | 2017

La Poule. Pratiques d'élevage et histoire culturelle

\title{
Noire géline pond blanc œuf ou Poules et poulaillers médiévaux
}

Black hen lays white egg or Chicken and medieval poultry houses

\section{Perrine Mane}

\section{(2) OpenEdition}

\section{Journals}

Édition électronique

URL : http://journals.openedition.org/ethnoecologie/3282

DOI : $10.4000 /$ ethnoecologie.3282

ISSN : 2267-2419

Éditeur

Laboratoire Eco-anthropologie et Ethnobiologie

Référence électronique

Perrine Mane, « Noire géline pond blanc œuf ou Poules et poulaillers médiévaux », Revue d'ethnoécologie [En ligne], 12 | 2017, mis en ligne le 18 décembre 2017, consulté le 19 avril 2019. URL : http:// journals.openedition.org/ethnoecologie/3282 ; DOI : 10.4000/ethnoecologie.3282

Ce document a été généré automatiquement le 19 avril 2019

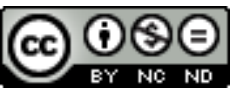

Revue d'ethnoécologie est mis à disposition selon les termes de la licence Creative Commons Attribution - Pas d'Utilisation Commerciale - Pas de Modification 4.0 International. 


\title{
Noire géline pond blanc œuf ou Poules et poulaillers médiévaux
}

\author{
Black hen lays white egg or Chicken and medieval poultry houses
}

\author{
Perrine Mane
}

1 De tout temps, historiens et archéologues médiévistes se sont davantage intéressés aux viandes nobles (la triade ovin, bovin et suidé) qu’à la volaille, généralement passée sous silence dans les grandes synthèses d'histoire des campagnes médiévales publiées dans les années 1970-1980. D'ailleurs, en 1981, l'historienne Maria Nada Patrone (Nada Padrone 1981: 285) n'hésite pas à définir avec un certain mépris la basse-cour comme caractéristique de la «petite économie de subsistance». Plusieurs explications de ce désintérêt peuvent être avancées; nous n'en citerons que deux: d'une part, les a priori issus de notre société occidentale moderne où le poulet s'est banalisé et dévalorisé, d'autre part, le fait que la basse-cour est avant tout le domaine de la femme et des enfants.

2 En fait nombreux et variés sont les documents, tant archéologiques qu'écrits, qui soulignent l'importance de la volaille et des œufs dans le régime alimentaire de la population médiévale et attestent le rôle non négligeable tenu par les gallinacés non seulement dans la vie des campagnes mais aussi dans une économie urbaine en pleine croissance $^{1}$ : que ce soit, par exemple, parmi les sources écrites, les redevances en œufs ou en poulets énumérées dans les censiers ou les baux, les comptabilités judiciaires, les statuts de métiers, les recettes des traités culinaires ou, plus anecdotiquement, certains sobriquets ${ }^{2}$ tels que Pierre Oie, Adam Chapon ou encore Guillaume Le Coq.

3 L'iconographie confirme cette place importante des gallinacés. Si l'Ancien Testament ne contient que peu de références directes aux volailles, le Nouveau Testament montre à de multiples reprises le coq, en particulier comme un des symboles entourant le Christ lors de la Crucifixion, afin d'illustrer la trahison de saint Pierre ${ }^{3}$. Mais ce sont surtout les marges des ouvrages liturgiques qui sont peuplées d'oiseaux de la basse-cour: dès le $\mathrm{IX}^{\mathrm{e}}$ siècle, la poule est présente au fronton de plusieurs canons d'évangéliaires ${ }^{4}$, puis, du XIII ${ }^{\mathrm{e}}$ au $\mathrm{Xv}^{\mathrm{e}}$ siècle, les gallinacés occupent les marges des psautiers ${ }^{5}$ (Figure 13), des bréviaires ${ }^{6}$ 
ou des livres d'heures, telles les poules ou les oies emportées par le renard, encadrant l'enluminure de la trahison du Christ par Judas' (Figure 14).

4 Oies et poules sont également présentes dans les images du monde inversé : sur la miséricorde de la cathédrale de Saint-Claude ${ }^{8}$, le renard prêche aux oies; dans une tapisserie bâloise de la fin du $\mathrm{Xv}^{\mathrm{e}}$ siècle $^{9}$, il emporte sur son dos deux oies enfermées dans un sac, alors que dans des Heures à l'usage de Paris ${ }^{10}$, le coq fait cuire à la broche un renard. Aux siècles suivants, plusieurs manuscrits attribuent aux volatiles de la basse-cour des significations allégoriques: ainsi dans un exemplaire du début du $\mathrm{xVI}^{\mathrm{e}}$ siècle d'un Livre nommé Fleur de vertu, un coq qui chante sur un mur symbolise «la réjouissance »"

5 À la fin du Moyen Âge, les gallinacés deviennent surtout les protagonistes de nombreux récits profanes. Le coq est par exemple indissociable de la déesse Aurore qui ouvre les portes de la nuit dans l'Épître d'Othéa de Christine de Pizan ${ }^{12}$, ou encore, dans une des nouvelles du Décaméron de Boccace ${ }^{13}$ (Figure 7), c'est sous une cage à poules que se cache, dans la demeure de Pietro di Vinciolo, un jouvenceau convoité par la maîtresse de maison. Fables et proverbes illustrés, qui connaissent un véritable engouement au Moyen Âge, ne sont pas en reste. Que ce soit les fables de «La femme et la poule ${ }^{14}$ et $~ «$ Des coqs et de la perdrix " ou le proverbe "Sauter du coq à l'âne " ${ }^{15}$, tous sont prétexte à des illustrations en relation avec la basse-cour. Enfin, aux côtés du loup Ysengrin et de Renart le goupil, Chanteclerc, le coq et Pinte et Copette, les deux poules, jouent un rôle prépondérant dans le Roman de Renart dont les copies se multiplient à partir du XIII ${ }^{\mathrm{e}}$ siècle.

Parallèlement à cette littérature profane, aux $\mathrm{Xv}^{\mathrm{e}}$ et $\mathrm{XVI}^{\mathrm{e}}$ siècles, les volatiles sont mêlés à des scènes agraires moins fantaisistes, notamment dans nombre de calendriers flamands ${ }^{16}$ (Figure 5) ; ils occupent aussi une place de choix dans les bestiaires ${ }^{17}$, en particulier dans le De avibus, sorte de bestiaire moralisé, consacré aux seuls oiseaux, rédigé vers 1150 par Hugues de Fouilloy ${ }^{18}$. Les encyclopédies, comme le De proprietatibus rerum de Barthélemy l'Anglais ${ }^{19}$, le De animalibus d'Albert le Grand ou encore le Livre du Trésor de Brunet Latin, réservent elles aussi de longs développements aux oiseaux, et en particulier au coq. Quant au Tacuinum sanitatis, traité d'hygiène écrit au xi siècle par un médecin de Bagdad, abondamment copié et enluminé aux XIV et $\mathrm{XV}^{\mathrm{e}}$ siècles, il consacre des rubriques entières aux coqs, mais aussi aux oies, aux pigeons et aux œufs.

\section{Composition de la basse-cour médiévale}

7 La composition de la basse-cour médiévale dépend de la région, de l'époque, des habitudes culturelles, mais surtout du milieu social : on relève en effet une très nette distinction entre habitat castral et paysan. Au IX ${ }^{e}$ siècle, parmi les volatiles élevés sur les domaines impériaux, le capitulaire De villis mentionne, à côté des poules, des oies et des canards, les paons, les faisans, les colombes, les tourterelles et les perdrix. Cette énumération est révélatrice de l'influence des agronomes antiques ${ }^{20}$. $\mathrm{Au} \mathrm{XI}^{\mathrm{e}}$ siècle, les fouilles du château de Mehun-sur-Yèvre (Cher) témoignent déjà de la présence du paon (Jouanin 2011: 340 et 363). Plus tardivement, puisqu'elle date du début du XIV siècle, la basse-cour d'un domaine modèle de type aristocratique décrite par le Bolonais Pietro de' Crescenzi dans son traité d'agriculture, l'opus ruralium commodorum, doit accueillir paons, faisans, oies, canards et poules, mais également des coulons, des tourterelles, des merles, des perdrix et des cailles à engraisser ${ }^{21}$. En fait dans la basse-cour aristocratique, la diversité des volatiles répond non seulement à l'exigence d'un élevage pour la 
consommation alimentaire, mais surtout à la présence d'oiseaux d'agrément. Canards, faisans et autres poules de races exotiques pouvaient présenter le même plaisir visuel que le cygne, le paon ou la grue, qui arpentent les jardins et les cours dans les images de la fin du Moyen Âge ${ }^{22}$, pour des raisons esthétiques évidentes. Ainsi, au xve siècle, au château d'Angers, les appartements seigneuriaux donnent d'un côté sur les volières, de l'autre sur la basse-cour.

En milieu rural, nous ne retrouvons pas cette diversité : en effet, ce sont essentiellement les poules et les coqs qui sont présents, constituant d'ailleurs la majorité des redevances en nature. Quand ils ne sont pas seuls, sont mentionnés les oies et plus rarement les canards. Ainsi, pour ne donner qu'un exemple, Léopold Delisle (Delisle $1851: 269$ ) relève, en s'appuyant sur des documents comptables concernant la très grande majorité des cours de ferme de la Normandie médiévale, qu'on n'élevait généralement que deux espèces de volailles : les poules et les oies. L'iconographie confirme bien cette absence de diversité dans la basse-cour du paysan où oies, mais surtout poules se côtoient ${ }^{23}$.

\section{«Aux plumes cognoit-on l'oiseau »}

Le croisement des sources documentaires permet de relever plusieurs caractéristiques morphologiques des gallinacés, en particulier leur taille et leur plumage. Poules et coqs de l'époque médiévale se distinguent par une certaine gracilité et des gabarits modestes ${ }^{24}$. En effet, durant le haut Moyen Âge, on relève une chute brutale, de l'ordre de $6 \%$, de la taille des gallus ${ }^{25}$ (Clavel et al. $1996: 3-12$ ), qui aboutit au $\mathrm{X}^{\mathrm{e}}$ siècle au niveau le plus bas des périodes historiques, sans doute du fait de la perte des savoir-faire romains et gaulois. Ce n'est qu'à partir du Moyen Âge classique que s'amorce un net redressement qui se stabilise $\mathrm{au} \mathrm{Xv}^{\mathrm{e}}$ siècle, période où la taille des gallinacés redevient équivalente à celle du Haut-Empire romain.

10 La présence de races de poules de petite taille est attestée dès l'Antiquité. Ainsi Pline l'Ancien ${ }^{26}$ constate-t-il qu' « il y a aussi une espèce naine qui n'est pas stérile, ce qu'on en voit chez aucun autre oiseau ; mais rarement ces naines pondent à époque fixe, et leur incubation est nuisible aux œufs ». Au XI ${ }^{\mathrm{e}}$ siècle, le castrum d'Andone, en Charente, a livré deux races de poules, la première assez communément retrouvée sur d'autres sites d'époque voisine, et la seconde, beaucoup plus petite et plus rare (Grenouilloux \& Migaud 1993 : 163-176). Plus tardivement, les sites du château de Chevreuse (Yvelines) au XIv ${ }^{\mathrm{e}}$ siècle ou celui d'Orléans au $\mathrm{XVI}^{\mathrm{e}}$ ont eux aussi fourni quelques ossements isolés de gallinacés de taille fort réduite (Clavel et al. 1996: 3-12 et Borvon 2012: 230 et sq.). Ces vestiges semblent attester le maintien de formes naines au Moyen Âge, mais ils démontrent également une diffusion peu importante de ces poules durant cette période, comme le confirment d'ailleurs les images, qui ne les représentent jamais. Il est vrai que l'iconographie n'est que d'un secours fort relatif pour connaître la taille des volatiles, puisque, durant tout le Moyen Âge, les artistes ne tiennent pas compte des proportions et adoptent une représentation hiérarchique, cherchant à mettre en valeur certains objets ou certains détails aux dépens d'autres.

11 En revanche, à travers les enluminures, la couleur du plumage est nettement représentée. Les plumes rousses et noires sont largement majoritaires aussi bien pour les poules que pour les coqs, suivant en cela les recommandations de Pietro de' Crescenzi : «qui veut avoir bon poulailler doit choisir des poules bonnes pondeuses, à plumes rouges et pennes 
noires $\|^{27}$. Dès le $\mathrm{X}^{\mathrm{e}}$ siècle, dans l'Évangéliaire de Blois ${ }^{28}$, tout comme aux XIV et $\mathrm{XV}^{\mathrm{e}}$ siècles, la couleur brune se retrouve dans des manuscrits italiens, par exemple dans un Bréviaire siennois $^{29}$ et un Tacuinum lombard ${ }^{30}$, mais aussi dans de nombreux manuscrits français, telles les marges des Heures de Marguerite d'Orléans ${ }^{31}$ ou dans un Livre des propriétés des choses de Barthélemy l'Anglais ${ }^{32}$.

Tout aussi nombreux sont les plumages noirs, notamment sur la mosaïque de San Clemente de Rome au XII ${ }^{\mathrm{e}}$ siècle (Figure 10), comme à la fin du XIv siècle dans un Tacuinum $^{33}$ enluminé à Pavie ou encore au $\mathrm{xv}^{\mathrm{e}}$ siècle (Figure 3), dans une fable de «La femme et la poule » d'Ésope enluminée à Florence ${ }^{34}$, mais aussi dans un Épitre d'Othéa flamand décoré à Lille ${ }^{35}$. Quant à la couleur blanche, Columelle, dans son De re rustica ${ }^{36}$ - et, à sa suite, l'ensemble des agronomes latins - conseille de l'éviter car ces poules "sont presque toujours sans vigueur, peu vivaces et rarement fécondes. Mais surtout cette couleur [...] les expose davantage à être enlevées par les éperviers et les aigles ». Ces recommandations sont largement reprises au Moyen Âge, comme en témoigne par exemple au XIII siècle, l'encyclopédiste Brunet Latin dans son Livre du trésor ${ }^{37}$ : «Pour ce doit li sires de sa maison eslire geline noires ou grises et eschivre [éviter] les blanches. » Les enlumineurs suivent ces conseils puisque les volatiles blancs sont rares dans la bassecour et, quand ils sont présents, poules et coqs blancs relèvent le plus souvent de l'emblématique ou bien ornent le haut d'un cimier ${ }^{38}$.

Le plumage peut également être panaché, mêlant plumes noires et rousses comme pour les poules d'une Bible castillane ${ }^{39}$ ou celles d'un Psautier anglais ${ }^{40}$, mais aussi pour le coq d'un exemplaire des Secrets de l'histoire naturelle ${ }^{41}$, peint par l'Angoumois Robinet Testard vers 1485 . Ce dernier animal semble d'ailleurs bien répondre à la description de l'animal idéal transcrite par Pietro de' Crescenzi ${ }^{42}$ :

«Les coqs doivent être grands et hauts, de bonne poitrine, rouge crête, court bec lisse et aigu, les yeux hardis et noirs à paille rouge, le cou bariolé ou doré, les cuisses courtes, blanches, velues, les ongles grands, la queue à plusieurs pennes $[\ldots] »$.

Il est à noter que, d'après l'iconographie, des gallinacés de races différentes semblent fréquemment se côtoyer dans le même poulailler. Ainsi, dans un Bréviaire flamand du début du XVI ${ }^{\mathrm{e}}$ siècle, des poules aux plumes blanches picorent auprès d'autres de couleur brune $^{43}$, tandis que, dans un Livre des propriétés des choses de Barthélemy l'Anglais ${ }^{44}$ (Figure 1), la basse-cour est composée de poules brunes, grises, noires et même blanches. 
Figure 1 : Basse-cour de maison aristocratique. Barthélemy l'Anglais, Livre des propriétés des choses , enluminé vers 1480 dans le Berry, par Évrard d'Espinques

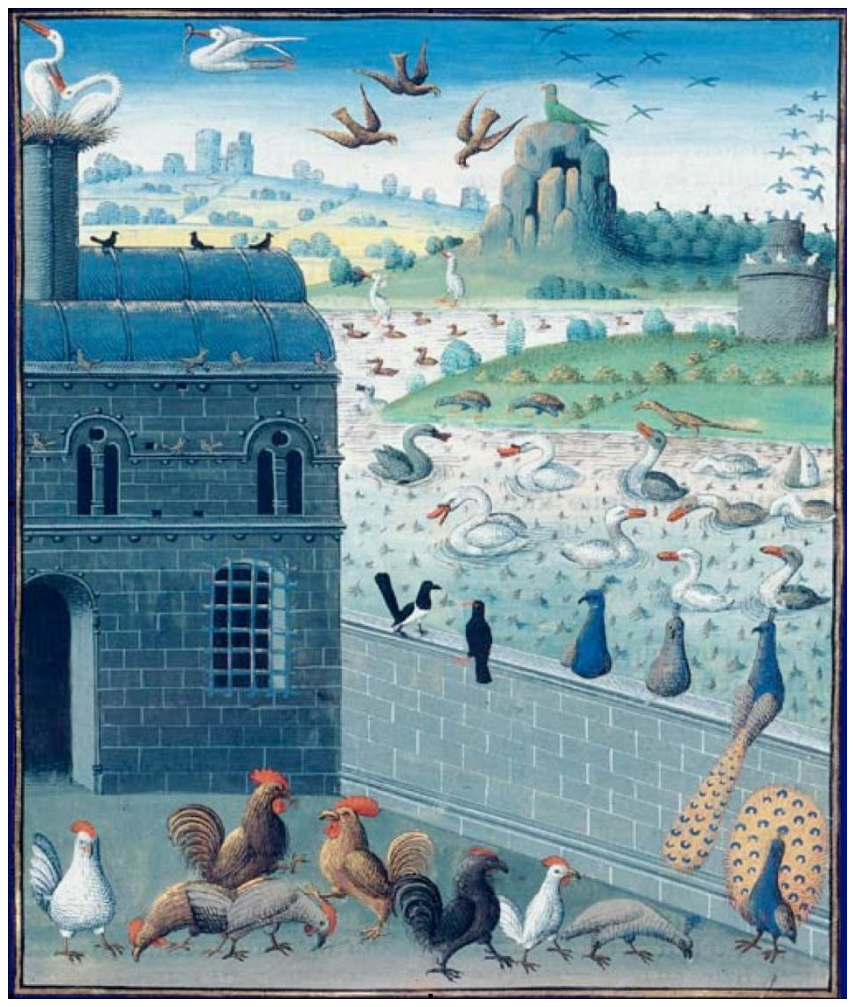

Paris, BnF, Français 9140, f. 211

Il est une caractéristique que seuls donnent les agronomes et les encyclopédistes et que ni l'archéologie, ni l'iconographie ne peuvent nous transmettre : c'est le chant du coq ${ }^{45}$. Tous ne sont pas d'accord: si Crescenzi conseille d'avoir dans sa basse-cour un coq qui chante souvent ${ }^{46}$, les différentes versions du Tacuinum sanitatis divergent: selon le manuscrit conservé à Liège ${ }^{47}$, les meilleurs coqs sont ceux qui ont une voix bien timbrée, tandis que l'exemplaire de Vienne ${ }^{48}$ préconise les coqs qui n'ont pas trop de voix.

\section{Poulaillers et autres aménagements mobiliers destinés aux gallinacés}

Le poulailler - ou plutôt la galinière ou la gélinière, selon les dénominations médiévales est essentiellement documenté par l'iconographie car, à la différence des agronomes antiques ou de l'époque moderne, très précis sur ce sujet, les traités médiévaux, tel celui de Pietro de' Crescenzi, ne donnent que fort peu d'indications sur les aménagements mobiliers de la basse-cour. Ce silence se retrouve dans les documents archivistiques comme les inventaires après décès : pour les $\mathrm{XIV}^{\mathrm{e}}$ et $\mathrm{XV}^{\mathrm{e}}$ siècles, Françoise Piponnier ne relève pas une mention de poulailler sur un corpus de deux cent trente inventaires dijonnais énumérant les noms des différentes pièces de l'habitation prisée (Piponnier 2006 : 109-116). L'archéologie n'est guère plus prolixe : en effet, exceptionnelles sont les découvertes de poulaillers ${ }^{49}$, l'élevage des volailles ne laissant que peu d'empreintes au sol, d'autant plus que leurs abris sont souvent situés en hauteur; or, en archéologie, les étages ne laissent guère de traces. De plus, dans nombre de maisons, il ne devait même 
pas exister d'espaces ou de logements exclusivement dévolus au poulailler, les volailles étant logées à l'étable avec les bovidés, voire avec les chevaux, ou encore dans une grange, tandis que dans les maisons mixtes, un même toit abritait hommes et animaux, surtout les mammifères et sans nul doute aussi les volailles.

En revanche, l'iconographie permet de distinguer différents types d'aménagements destinés aux gallinacés, bien que, comme nous venons de le voir, il soit assez exceptionnel que la basse-cour dispose d'une construction indépendante. Pourtant, dès 830, dans un Physiologus ${ }^{50}$ peint à Reims, des poules sont abritées sous trois arcades et une décennie plus tard, le plan de l'abbaye de Saint-Gall dessine deux espaces circulaires couverts d'un dôme, définis pour l'un comme "pullorum hic cura et perpes nutritio constat " et l'autre comme un logement pour les oies : «anseribus locus hic pariter manet aptus alendis». Au XIV ${ }^{\mathrm{e}}$ siècle, dans un exemplaire du Roman de Renart ${ }^{51}$ (Figure 2), le poulailler, qui est constitué de murs en moellons jointoyés, est lui aussi couvert d'un toit en coupole, type de construction particulièrement recommandé deux siècles plus tard par Olivier de Serres ${ }^{52}$. Pour lui,

«Les meilleurs poulaillers sont voûtés par le dessus, attendu que la poulaille sera plus chaudement en hiver, et plus fraîchement en été, et moins importunée des souris, belettes, fouines et semblables bêtes, sous les voûtes que sous les planchers, ni simples couvertures. »

Figure 2 : Poulailler aux murs en moellons et au toit en coupole. Roman de Renart, enluminé au XIV siècle en France

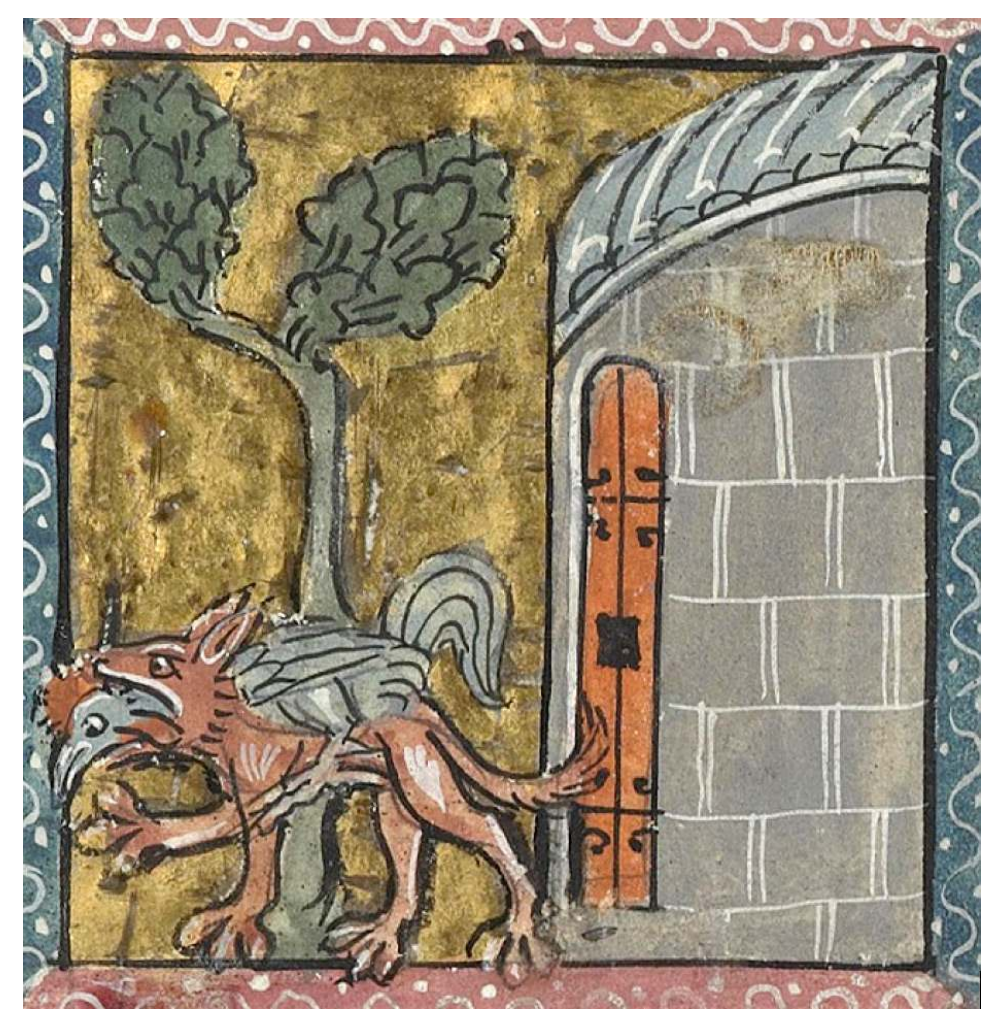

Paris, BnF, Français 1580, f. 20

Dans l'enluminure de la fin du XIV ${ }^{\mathrm{e}}$ siècle d'un Tacuinum lombard ${ }^{53}$ (Figure 3), le dispositif est tout à fait différent puisque le poulailler repose sur des pilotis d'environ deux mètres de haut, utile protection contre d'éventuels prédateurs; seule une échelle permet d'y accéder. Abritée par un toit à deux pentes constitué de tuiles canal, la construction ne 
dépasse pas une soixante de centimètres de côté et sa forme se rapproche de celle des niches de chien. Une arche percée sur la façade permet à la fermière de passer son bras pour accéder aux nids, tandis que, sur un des côtés perpendiculaires, une petite arcade se prolonge par un perchoir. S'il est difficile de déterminer précisément à quel milieu social correspond cet édifice, il semble évident, si l'on se fie aux bâtiments alentour et aux costumes soignés des femmes qui s'occupent des poules, que nous ne sommes pas chez de petits tenanciers.

Figure 3 : Poulailler sur pilotis. Rubrique : Fuf de poules. Ibn Butlan, Tacuinum sanitatis, vers 1395 en Lombardie

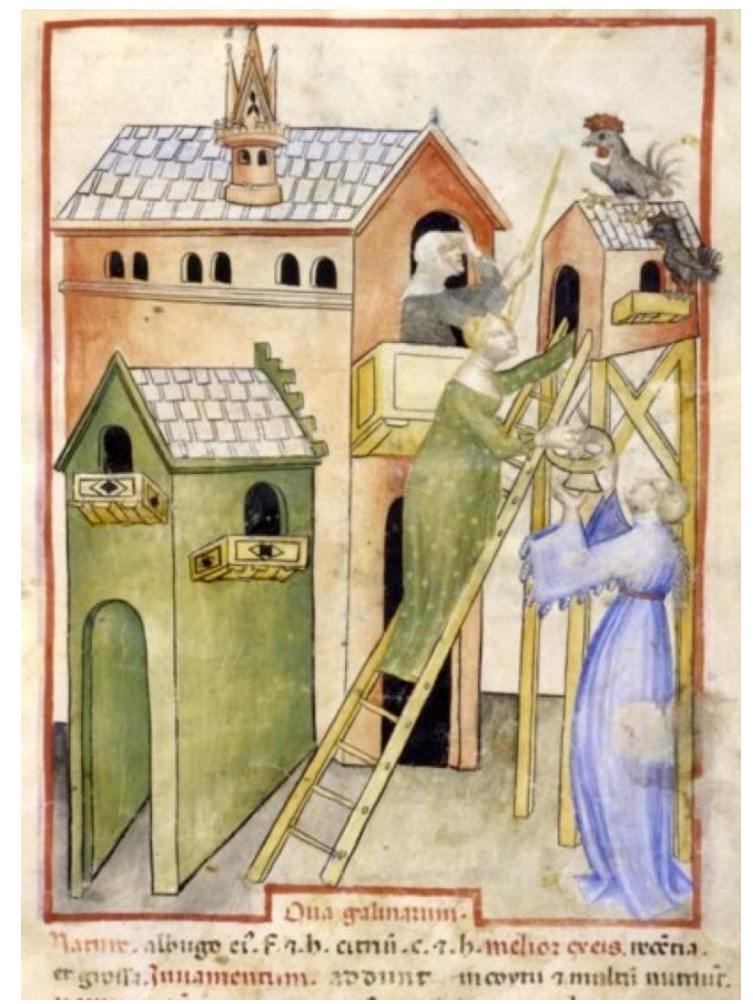

Paris, BnF, Nal 1673, f. 60

En tout cas, il est impossible, à travers ces images, d'affirmer que le poulailler est orienté selon une direction particulière. Les traités médiévaux ne donnent pas plus de précision sur ce point. Olivier de Serres, quant à lui, à la suite des agronomes antiques ${ }^{54}$, insiste sur la nécessité de bien orienter le poulailler et conseille que les «principales vues [soient] tournées vers l'Orient d'hiver afin que la poulaille soit échauffée du soleil à son lever $\aleph^{55}$.

Plus fréquemment, le poulailler n'est pas une construction indépendante. Ainsi dans plusieurs enluminures lombardes du Tacuinum sanitatis ${ }^{56}$ (Figure 4), les poules sont abritées dans une simple resserre, partie intégrante de la maison puisqu'un étage muni de fenêtre le surmonte. Rien ne distingue cette pièce, à l'exception d'une échelle et de quelques poutres à l'intérieur permettant aux volatiles de se percher et surtout une porte percée de nombreux trous procurant aération et lumière tout en empêchant les oiseaux de sortir - mais pas les poussins. 
Figure 4 : Resserre pour les poules, au sein même de l'habitation. Rubrique : CEuf de poules. Ibn Butlan, Tacuinum sanitatis, enluminé vers 1450 en Rhénanie

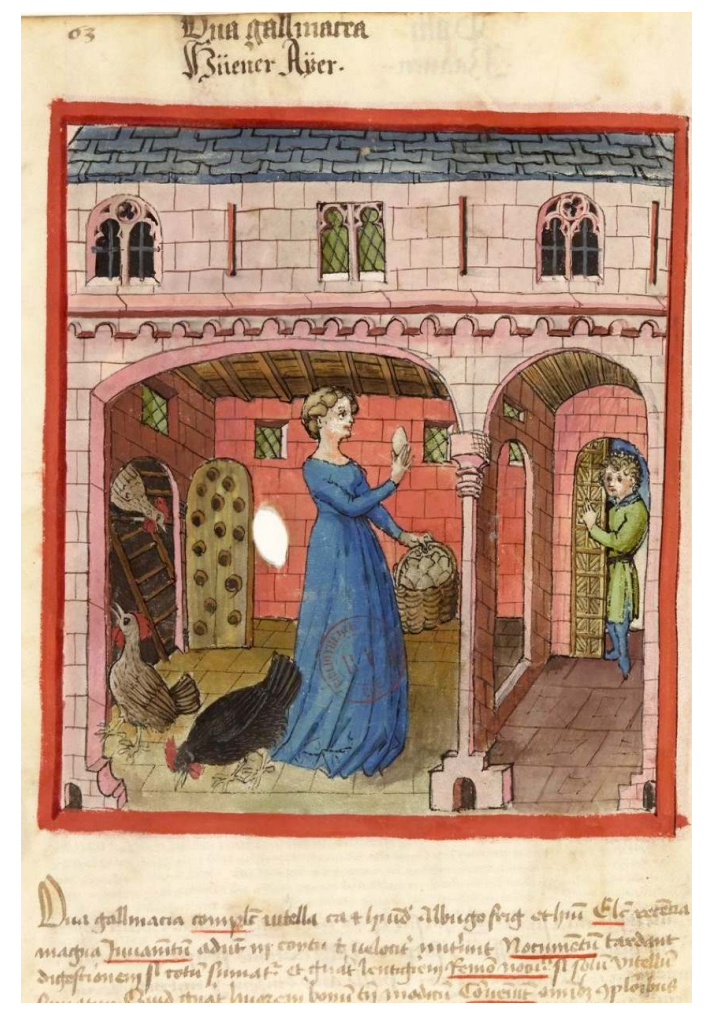

Paris, BnF, Latin 9333, f. 63v

Dans plusieurs Livres d'heures flamands du début du XVI $\mathrm{e}^{\mathrm{e}}$ siècle, ce sont les combles d'un bâtiment de l'exploitation agricole qui sont réservés aux gallinacés. L'accès des volatiles à ces abris surélevés se fait généralement par une échelle extérieure, le plus souvent constituée de barreaux fixés de part et d'autre d'une poutre centrale ${ }^{57}$ (Figure 5) ou par des soliveaux encastrés dans la construction ${ }^{58}$. Dans l'iconographie, ces poulaillers peuvent être logés au-dessus de l'étable ${ }^{59}$ ou encore surmonter la bergerie ${ }^{60}$. Dans la description du manoir de Fontains-lez-Nangis, en Brie, rédigée en 1377, il est mentionné « Un gelinier et dessoubz une estable à mettre pourceaux $»^{61}$. 
Figure 5 : Poulailler dans les combles au-dessus de l'étable. Heures de la Vierge d'Hennessy, enluminées vers 1530 à Bruges, par Simon Bening et son atelier

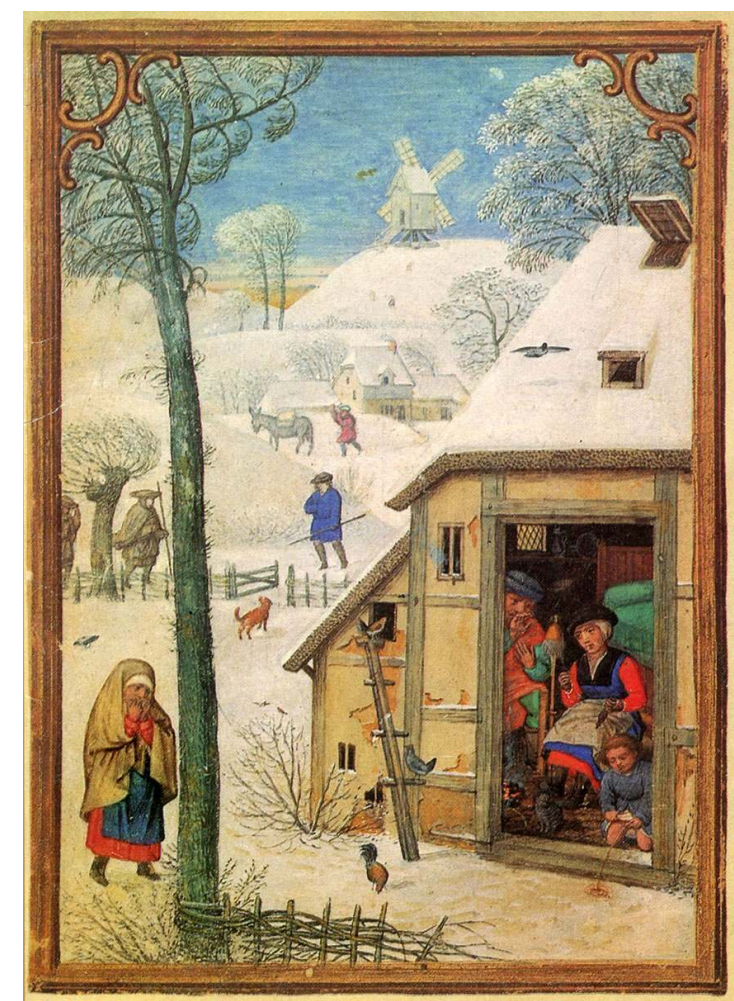

Bruxelles, Bibl. Royale, ms. II. 158, f. 1

En revanche, les images ne montrent pas de poulailler édifié à proximité de source de chaleur, alors que Columelle conseillait de le positionner près du four ou de la cuisine de telle manière que la fumée parvienne à la volaille parce qu'elle lui est salutaire. Encore au $\mathrm{XVI}^{\mathrm{e}}$ siècle, Olivier de Serres préconise d'installer les pondeuses « derrière le four à cuire le pain » pour qu'elles soient « chaudement accommodées et hors de bruit $»^{62}$.

Il est à remarquer que, à l'exception des portes fermées percées de trous des Tacuina sanitatis, aucune image ne montre d'aménagement particulier pour protéger les poulaillers, alors que Pietro de' Crescenzi conseille de les munir de cages (appelées cavea) et de les clore la nuit ; contre les rapaces, une couverture végétale, constituée par une vigne ou une clématite, se révèle, selon lui, une défense efficace ${ }^{63}$. Au Xvi ${ }^{e}$ siècle, Olivier de Serres, dans son Théâtre d'agriculture, insiste sur le fait que les ouvertures du poulailler doivent pouvoir être obturées, en particulier

« la fenêtre pour sureté, sera ferrée avec des barreaux de fer mis dans l'épaisseur du mur, et au-devant d'iceux plaqué un petit treillis de fer d'archal fait à la façon de cage pour empêcher l'issue à la poulaille et l'entrée aux rats, fouines, belettes et semblables ennemis des poules ".

Quant au sol, il sera

« carrelé avec de la brique ou avec des pierres taillées; à ce que les rats ni les serpents n'y puissent avoir entrée $»^{64}$.

Outre ces poulaillers en dur, deux Tacuina sanitatis, l'un lombard de la fin du XIV siècle ${ }^{65}$ (Figure 6), l'autre rhénan du milieu du Xve ${ }^{e}$ siècle $^{66}$, montrent une structure mobile. L'abri léger est parallélépipédique dans la version italienne, en forme d'arche dans l'exemplaire 
rhénan. Ces poulaillers qui mesurent un peu plus d'un mètre de haut, sont fabriqués soit en éclisses d'osier tressées sur clayonnage, soit en boudins, sans doute de paille de seigle. Ils reposent sur une planche de bois qui les isole du sol. Sur un des côtés, une planche est découpée d'une ouverture dénommée poulière qui permet aux volatiles d'entrer et sortir, mais également percée dans sa partie supérieure de petits orifices afin d'offrir une bonne aération. Ces " galinières ", disposées à proximité de la maison, ont pour avantage majeur d'être facilement déplaçables, grâce à leur faible poids.

Figure 6 : Structure mobile pour les poules. Rubrique : Poules. Ibn Butlan, Tacuinum sanitatis, enluminé vers 1450 en Rhénanie

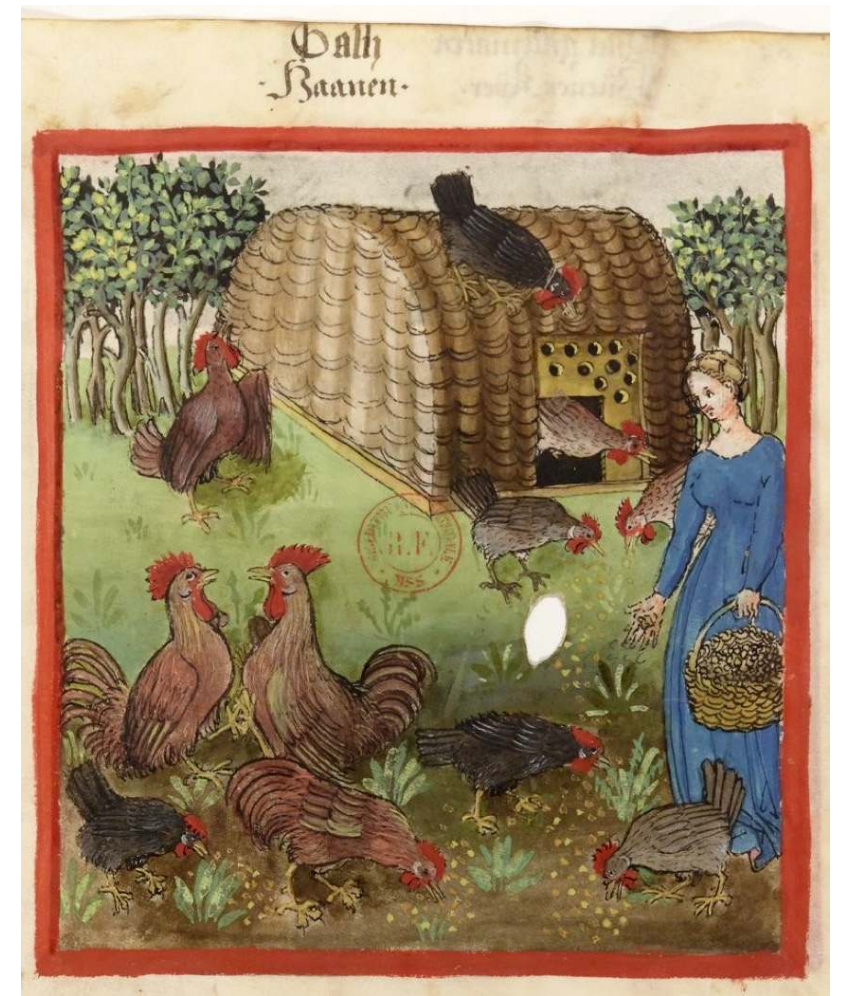

Paris, BnF, Latin 9333, f. 63

D'autres types de cages, mobiles, sont également installées à l'intérieur de la maison paysanne, mais aussi urbaine, puisque nombreux sont les habitants des villes qui élèvent quelques volatiles. Ainsi, dans plusieurs exemplaires français ${ }^{67}$ ou flamands ${ }^{68}$ (Figure 7) du Décaméron, l'aménagement est succinct : deux poules sont abritées dans une simple caisse parallélépipédique de cinquante centimètres de haut pour deux mètres de long environ, fermée sur un des grands côtés par des barreaux. Placé dans la maison, au pied d'un escalier, cet abri semble intégré à l'habitat: on en profite même pour déposer dessus certains objets. 
Figure 7 : Poulailler dans la maison. Boccace, Décaméron, enluminé vers 1440 dans le nord de la France

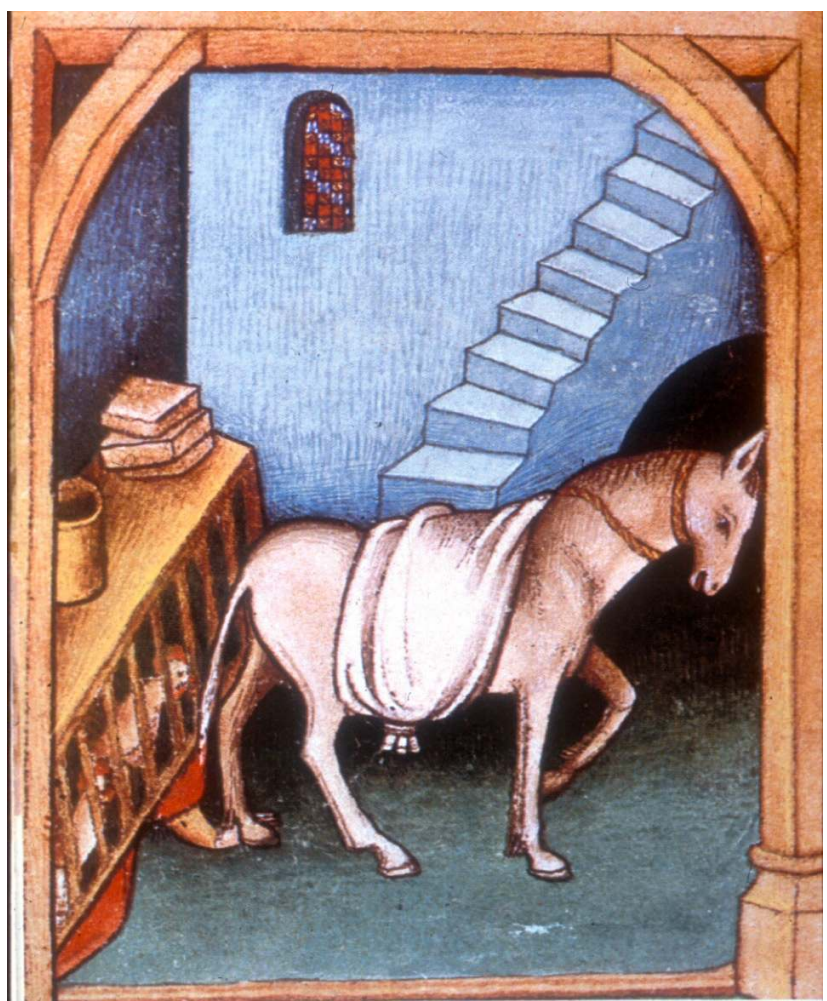

Paris, Arsenal, ms. 5070, f. 215v

L'iconographie nous renseigne également sur l'aménagement intérieur des poulaillers. L'élément le plus systématiquement figuré est le juchoir ${ }^{69}$ (Figure 8) qui est constitué d'un entrecroisement de poutres équarries auxquelles on accède grâce à une échelle. Il permet aux gallinacés de se reposer, en particulier la nuit, en hauteur, à l'abri des prédateurs, mais il leur évite aussi d'être en contact avec leurs fientes. Dans un Tacuinum enluminé par l'atelier lombard de Giovanni de'Grassi ${ }^{70}$, le juchoir, qui s'élève à environ un mètre cinquante au-dessus du sol, est constitué de perches parallèles ${ }^{71}$ soutenues par une armature de bois encastrée dans quatre piliers d'angle dont l'extrémité supérieure est en forme de U. Dans ce manuscrit, il est tantôt figuré à l'intérieur du poulailler pour illustrer la rubrique CEufs de poule (ova galinea), tantôt installé dans la cour, accolé à l'un des bâtiments d'exploitation de la ferme, à la rubrique consacrée aux coqs ${ }^{72}$ (Figure 8), sans doute afin de permettre aux volatiles de se reposer sans risque d'être dévorés. D'autres fois, comme dans des Euvres de Christine de Pizan ${ }^{73}$, le perchoir, appelé cette fois « juc », est plus modestement constitué d'une simple barre de bois, disposée en avancée sur l'un des murs de la maison; dans cette enluminure, il est protégé par un auvent en bois. 
Figure 8 : Juchoir. Rubrique : Poules. Ibn Butlan, Tacuinum sanitatis, enluminé à la fin du XIve siècle en Lombardie, par l'atelier de Giovanni de'Grassi

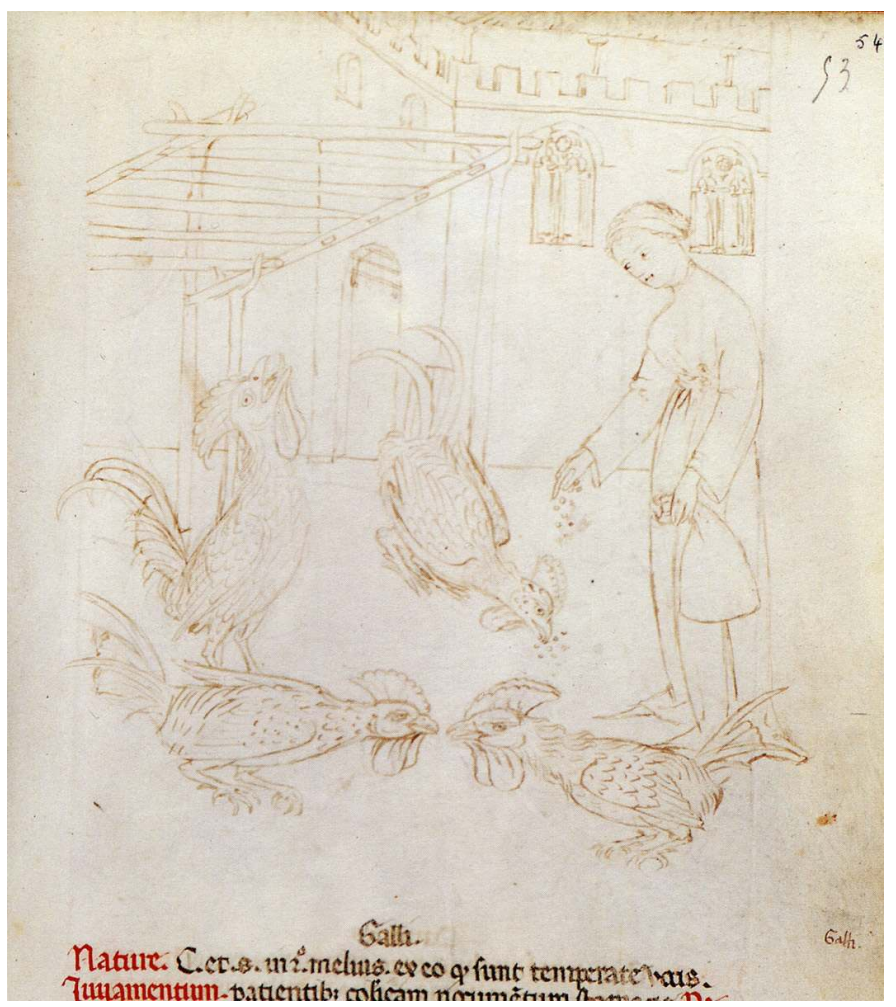

Liège, Bibl. Univ., ms. 1041, f. 54

L'intérieur du poulailler montre un autre type d'aménagement, les nichoirs ou pondoirs ${ }^{74}$ qui ont pour but d'éviter que les volatiles n'aillent pondre dans les espaces extérieurs. Si la poule se contente parfois d'un simple tas de paille disposé sur le sol, comme dans une Historia plantorum ${ }^{75}$, enluminée en Lombardie à la fin du XIV ${ }^{\mathrm{e}}$ siècle, la ponte s'effectue le plus souvent dans des cuvettes aux bords $\operatorname{bas}^{76}$ ou encore dans des paniers ${ }^{77}$ qui, à l'exception de la paille qui rembourre l'intérieur, ne diffèrent guère de ceux utilisés pour la récolte des fruits ou des légumes. Seul un Tacuinum ${ }^{78}$ (Figure 9) liégeois illustre la rubrique CEufs de poule par des niches aménagées dans l'épaisseur des murs. Une planchette ${ }^{79}$, légèrement débordante, sur laquelle a été disposée de la paille, est posée sur le fond de chacune de ces petites arches. 
Figure 9 : Nichoir. Rubrique : CEuf de poules. Ibn Butlan, Tacuinum sanitatis, enluminé à la fin du XIve siècle en Lombardie, par l'atelier de Giovanni de'Grassi

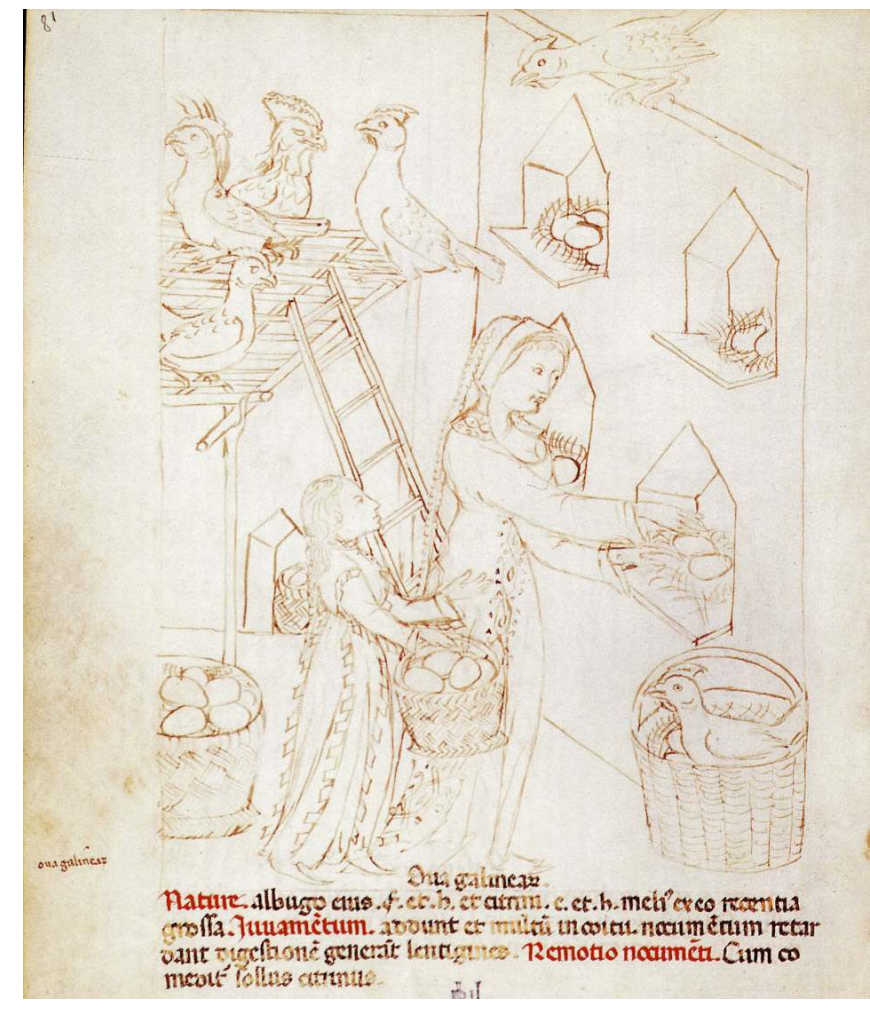

Liège, Bibl. Univ., ms. 1041, f. $41 \mathrm{v}$ visible dans l'iconographie : la mue. Sorte de cage en osier à claire-voie, elle est destinée à abriter la poule et ses petits après une période transitoire de quelques jours pendant laquelle les poussins sont logés sous les ailes de leur mère ${ }^{82}$. Pendant une quinzaine de jours, la mue demeure dans le poulailler et n'est sortie que de temps en temps dans un endroit bien exposé au soleil afin d'habituer les poussins à l'air ${ }^{83}$. Par la suite, elle est installée pour la journée entière au milieu de la cour de l'exploitation agricole. Dès le XII ${ }^{\mathrm{e}}$ siècle, la mosaïque de San Clemente de Rome (Figure 10) montre cette structure mobile de forme conique d'une soixantaine de centimètres de haut; on la retrouve au début du $\mathrm{XVI}^{\mathrm{e}}$ siècle dans l'Hortulus animae de Marguerite d'Autriche ${ }^{84}$. La mue permet de dresser les poussins avec le concours de la mère poule puisque, grâce à ses fines baguettes de bois espacées, les oisillons peuvent entrer et sortir librement tandis que la présence de la poule couveuse enfermée dans la cage les dissuade de trop s'éloigner ${ }^{85}$. Comme le préconise Crescenzi : "On doit laisser les petits poussins au soleil et sur le fumier pour qu'ils s'y ventrouillent : ils en deviendront plus forts ${ }^{86}$.» 
Figure 10 : Mue. Rome, San Clemente, mosaïque de l'abside, xII siècle

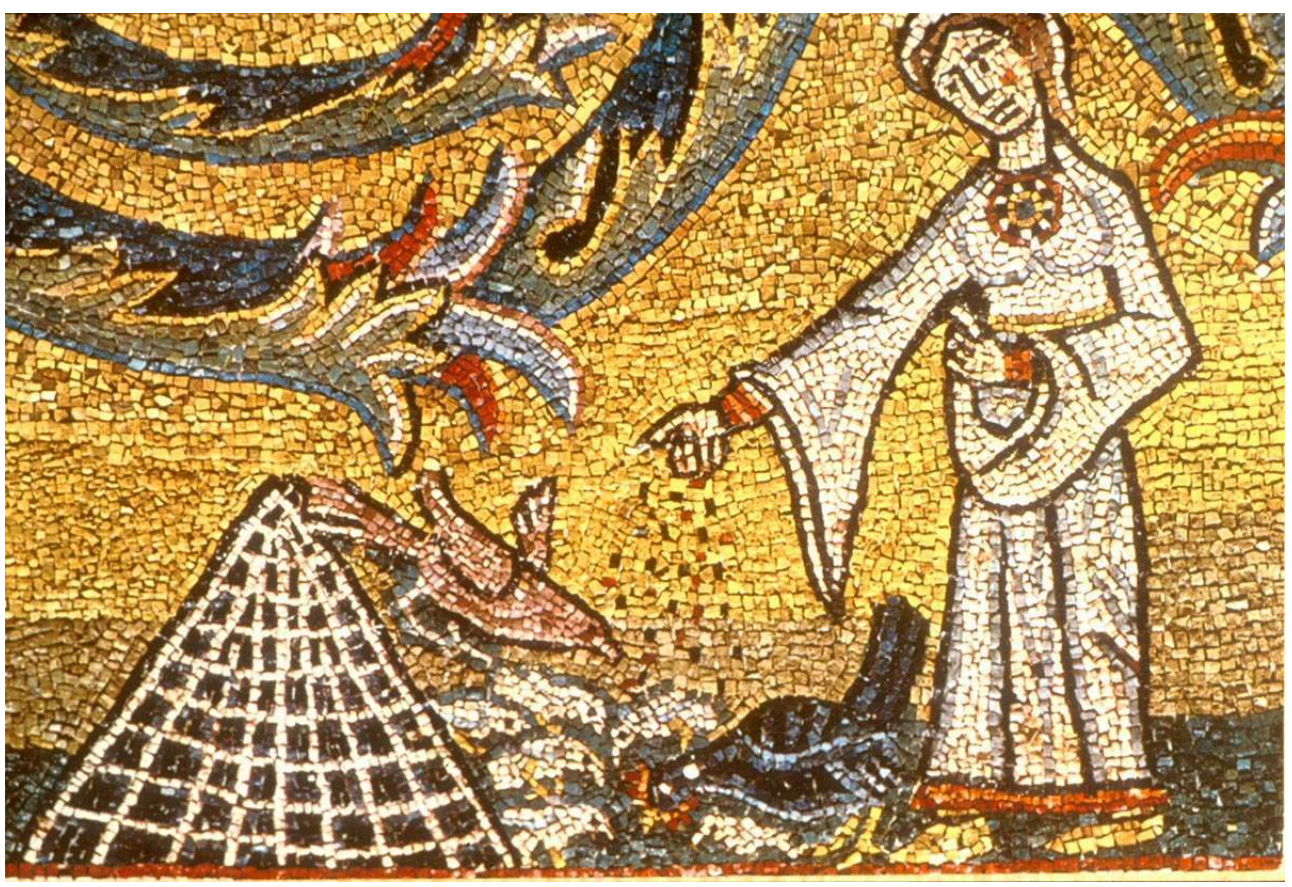

\section{«Qui naist de geline, il aime à gratter », ou le régime alimentaire des poules}

Dans l'iconographie relative à l'élevage des poules, une mangeoire destinée à alimenter les volatiles est parfois posée sur le sol ; c'est un simple pot doté d'un piédouche dans la Bible de Vivien ${ }^{87} \mathrm{du} \mathrm{IX}^{\mathrm{e}}$ siècle, une caisse parallélépipédique, vers 1020, dans une version limousine des Fables d'Ésope ${ }^{88}$ ou encore une petite auge d'une quinzaine de centimètres de côté dans le Psautier de Luttrell ${ }^{89}$ (Figure 13), enluminé vers 1340 dans l'est de l'Angleterre. Ces récipients sont-ils remplis de criblures, résidus des céréales les plus grossiers qui ne passent pas au crible et qui sont généralement réservés à la volaille? Il faut bien reconnaître que les images sont peu disertes sur le régime alimentaire réservé aux gallinacés alors que les agronomes antiques et modernes lui consacrent de longs développements. Par exemple, pour Columelle ${ }^{90}$, la nourriture qui convient le mieux aux poules est l'orge écrasée et la vesce ${ }^{91}$. Mais on peut aussi leur donner de menues criblures de froment, de l'ivraie bouillie ou encore du son auquel on aura laissé un peu de farine. La distribution épisodique de marc de raisin (aliment très bon marché) mélangé à des criblures de froment peut être profitable aux poules quand elles ont cessé de pondre ${ }^{92}$. Nous retrouvons ce même luxe de détails au $\mathrm{xVI}^{\mathrm{e}}$ siècle, par exemple chez Olivier de Serres ${ }^{93}$. Ce dernier conseille :

« outre la mangeaille, que cette volaille trouve en campagne convient lui donner du grain ou autre viande, deux fois le jour, avec ordinaire limité et heure certaine pour n'y faillir nullement [...]. Leur plus propre et ménageable pâture sont les millets communs, les vannures et criblures des blés qu'on sert à part pour cet usage ; auxquels [...] ajoute-t-on quelques fois du gland pilé, des herbes hachées, des fruits découpés et autres choses selon les saisons. Du son bouilli, et chaudement, leur donne-t-on pour l'épargne: et tant qu'on peut des miettes de la table pour les provoquer à pondre qu'à cela les conserve-t-on curieusement, comme l'on fait 
l'avoine pure, leur étant fort propre, le mil sarrasin aussi ; mais par-dessus toute autre viande, la graine de chanvre est de grande efficace à faire over ».

Si les traités d'agronomie médiévaux ne s'intéressent pas à la provende de la basse-cour, l'encyclopédiste Brunet Latin (reprenant en partie Columelle et Palladius), dans son Livre $d u$ trésor $^{94}$, recommande de distribuer aux gélines : « orge demi cuit, ki les fait engendrer et porter oes assés grans et larghement ». Par ailleurs, les comptes permettent parfois de saisir des régimes qui devaient être fort éloignés de ceux que les paysans réservaient à leurs poules. Ainsi, dans la basse-cour de l'archevêché de Bordeaux, poules, poulets et oies se partagent en 1361 quatre boisseaux de millet et un boisseau d'avoine (Houbbaida 1987 : 234). Ce goût pour les grains de millet est d'ailleurs souligné dans un Tacuinum lombard de la fin du XIV siècle où la rubrique consacrée à cette céréale est illustrée par une scène de dépiquage : tandis que les hommes guident deux bœufs sur l'aire de battage, une femme chasse avec sa quenouille une poule gourmande, accompagnée de ses deux poussins, qui tentent de dérober quelques grains ${ }^{95}$ (Figure 11).

Figure 11 : Poules picorant les grains lors du dépiquage du millet. Rubrique : Millet. Ibn Butlan, Tacuinum sanitatis, enluminé à la fin du XIVe siècle en Lombardie, par l'atelier de Giovanni de'Grassi

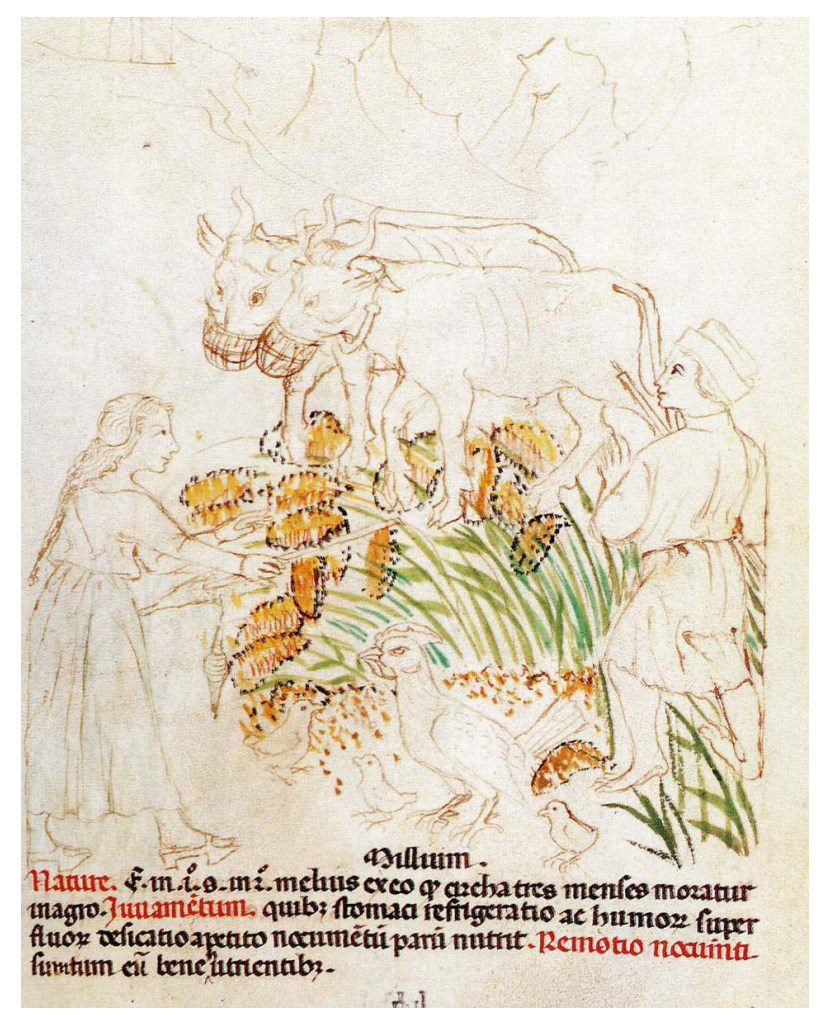

Liège, Bibl. Univ., ms. 1041, f. 31

Les images médiévales ne dépeignent aucun dispositif pour étancher la soif des gallinacés, alors que Columelle précise qu'il faut se méfier de l'eau croupie qui rend malades les volailles $^{96}$. Quant à Olivier de Serres, dans son Théâtre d'agriculture, il conseille d'installer devant le poulailler, un

«abreuvoir [...] des auges de pierre, ou de terre de potier cuite, ou de bois creusées proprement: dans lesquelles chaque jour mettre-t-on de l'eau fraîche et nette. Et afin qu'aucun bétail ne salisse l'eau sera bon de tenir toujours les auges couvertes seulement par-dessus, laissant les côtés à jour par lesquels les poules passant la tête 
s'abreuveront à plaisir ; et par ne pouvoir entrer dans l'eau, ne la remueront avec

les pieds et n'y fienteront [...] L'eau corrompue est très mauvaise à la poulaille $»^{97}$. oies trouvent une grande partie de leur pitance sur les friches, au bord des chemins ou dans les communaux dont elles mangent l'herbe (voir Bechman 1984:141), comme l'atteste par exemple une marge du Psautier de Luttrell ${ }^{106}$. Ces volatiles se déplacent souvent en bande et, dans les villages, l'usage voulait que le matin, chaque habitant ouvre la porte du réduit où les oies ont passé la nuit. Après s'être rassemblées, elles gagnent le pré communal, la rive du cours d'eau ou le bord du marais et y passent la journée, pour revenir au crépuscule en groupe au village (Grand \& Delatouche 1950 : 518). Pourtant, à travers l'iconographie, il n'est pas rare que les oies fassent partie du troupeau regroupant bœufs, chèvres et chevaux guidés vers la pâture par le berger, comme dans le Psautier de Stuttgart ${ }^{107}$, datant du $\mathrm{IX}^{\mathrm{e}}$ siècle. Encore au début $\mathrm{du} \mathrm{XVI}^{\mathrm{e}}$ siècle ${ }^{108}$, dans des Heures flamandes, à côté d'un troupeau de moutons, une oie isolée mange de l'herbe, les autres pataugeant dans un ruisseau. Les sources écrites comme les images attestent en effet que les oies sont le plus souvent surveillées, du moins quand elles s'aventurent en dehors de la cour de la ferme. Il est vrai que les dégâts occasionnés dans les champs ou les prés par la volaille peuvent être importants ${ }^{109}$. D'ailleurs, aux XIV et $\mathrm{XV}^{\mathrm{e}}$ siècles, la coutume de La Ferté-Avrain (en Sologne) interdit les prés aux oies (Guérin $1960: 96)^{110}$ et la coutume de Bazas, dans le Sud-Ouest, précise que chaque habitant «qui trouve des oies faisant des dommages dans son casal, son blé en grains ou dans sa vigne quand les raisins sont mûrs, peut leur arracher le bec jusqu'aux narines " ${ }^{111}$.

Le gardiennage peut être dévolu à un jeune garçon, tel Jean de Brie qui garda des oies dès l'âge de huit ans ${ }^{112}$. Cependant, plus souvent, ce sont des hommes: l'aucarius (Nada 
Padrone 1981 : 285) conduit ces volatiles, comme le confirment de nombreux documents iconographiques tel le berger du Bréviaire Grimani ${ }^{113}$ qui porte une besace à la main et un long bâton sur l'épaule ou celui d'une version gravée de l'Hortus sanitatis de Jean de Cuba ${ }^{114}$ (Figure 12) qui s'est muni d'une massue, à moins qu'une corne ne serve à regrouper le troupeau, comme dans le Missel de Jean de Foix ${ }^{115}$.

Figure 12 : Aucarius ou gardien d'oies. Hortus sanitatis de Jean de Cuba, 1517

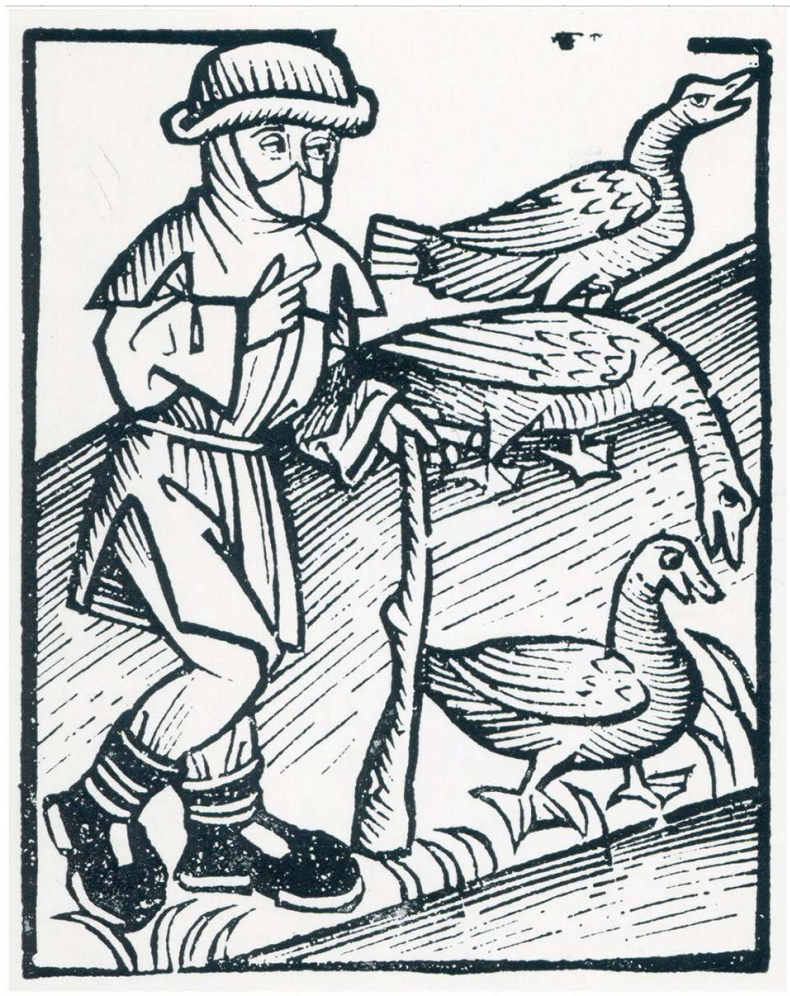

Paris, Sainte-Geneviève

Textes et iconographie attestent que la femme, bien que largement minoritaire, n'est pas exclue de la surveillance du troupeau d'oies. Par exemple en 1457, une Ordonnance du roi René mentionne «Itel, ungne fame, pour garder les oyes » (Kaiser-Guyot 1974 : 22) tandis que les marges entourant l'Arrestation du Christ des Heures de Marguerite d'Orléans ${ }^{116}$ (Figure 14) figurent une paysanne menaçant ces volatiles de sa quenouille. Plus tardivement, puisque daté de la fin du $\mathrm{Xv}^{\mathrm{e}}$ siècle, l'arrière-plan d'un tableau d'Hans Wertinger dit le Souabe, la Fête villageoise ${ }^{117}$, montre une jeune femme armée d'un bâton guidant une dizaine d'oies vers la pâture.

Pourtant ce partage des tâches ne se retrouve pas pour l'ensemble des soins donnés aux volatiles au sein de l'exploitation agricole : ils sont exclusivement réservés aux femmes, comme d'ailleurs nombre de tâches qui se déroulent à proximité ou dans la ferme (Mane 2004 : 31-58). Il est vrai que Palladius, dans son De re rustica ${ }^{118}$, affirmait déjà : « Il n'y a pas une femme, pour peu qu'elle soit intelligente, qui ne sache élever des poules. » Encore au $\mathrm{xVI}^{\mathrm{e}}$ siècle, Olivier de Serres dans son Théâtre d'agriculture ${ }^{119}$ énonce avec mépris que «la nourriture de la poulaille est si vulgaire qu'il semble être chose utile d'en traiter particulièrement, étant doctes en ce gouvernement, les plus simples femmelettes ». Au Moyen Âge, c'est donc aux femmes qu'incombe le soin de nourrir la basse-cour, de surveiller les volatiles dans l'enceinte de la ferme et également de ramasser les œufs. 
40

\section{s'en charge. Dans une marge du Psautier de Luttrell ${ }^{120}$ (Figure 13), la paysanne, entourée de poules, la quenouille enfilée sous la ceinture, verse une écuelle dans une petite auge. C'est tantôt dans le creux de sa robe, comme dans la mosaïque de San Clemente de Rome (Figure 10), tantôt dans un panier d'osier ${ }^{121}$ (Figure 6) ou encore dans un sac de toile comme dans un Tacuinum lombard ${ }^{122}$ (Figure 8) que sont contenus graines et rebuts du repas. \\ Figure 13 : Fermière nourrissant les poules. Psautier de Luttrell, enluminé vers 1330 dans l'est de l'Angleterre}

les rares images où de la nourriture est distribuée aux poules, c'est la fermière qui

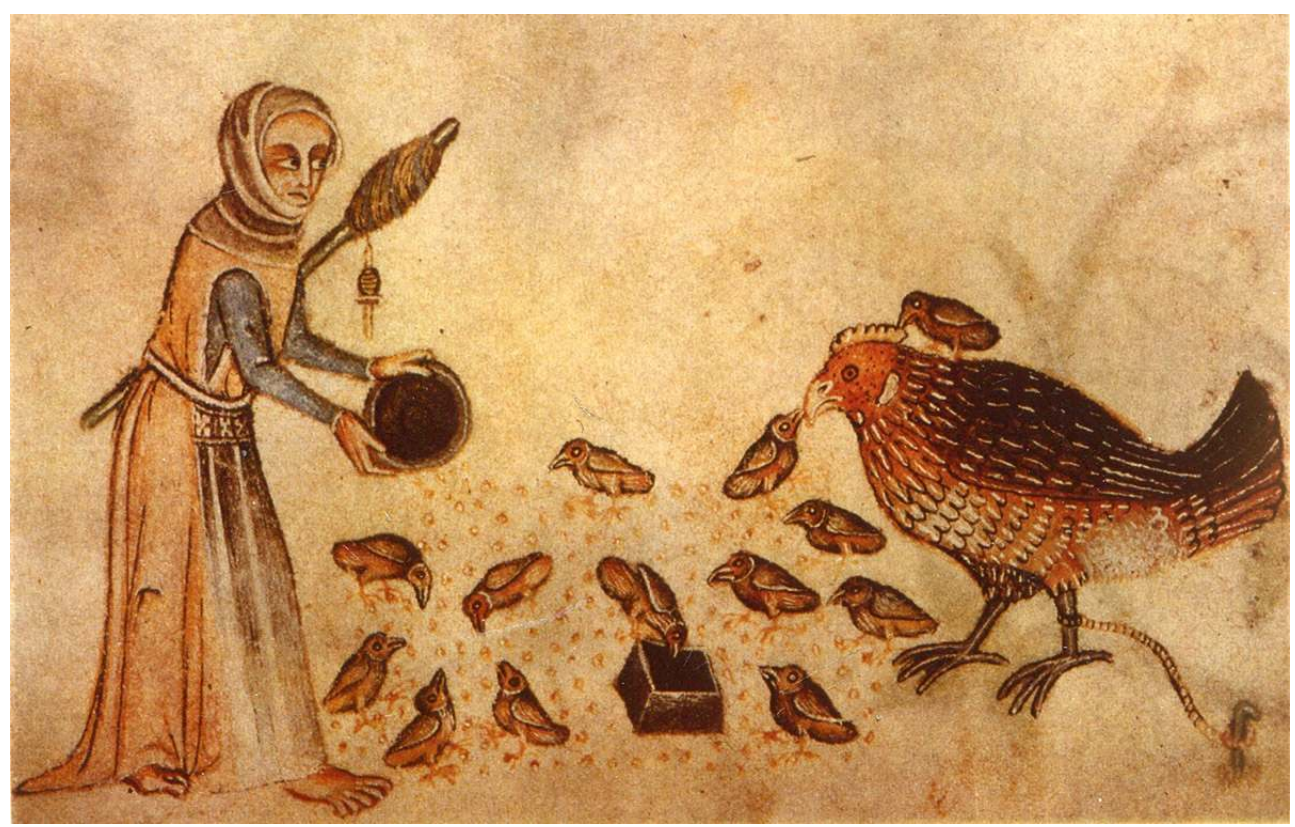

LONDRES, BL, ADD. 42130, F. 166V - BRITISH LIBRARY BOARD

La femme est également chargée de surveiller la volaille et de prévenir les attaques des animaux prédateurs. Dans l'iconographie médiévale, fort nombreuses sont les enluminures, qui reprennent le thème de la volaille emportée par le renard ${ }^{123}$ (Figure 14), mais aussi par des oiseaux de proie qui visent avec prédilection les poussins, notamment dans une Bible castillane ${ }^{124}$ ou dans un Livre des vertus ${ }^{125}$, ou même par des chats, comme au $\mathrm{XV}^{\mathrm{e}}$ siècle, dans un Faits et dits mémorables de Valère Maxime ${ }^{126}$. 
Figure 14 : Fermière défendant ses poules du renard. Heures de Marguerite d'Orléans, enluminées vers 1430 à Rennes. Latin 1156 B, f. 133

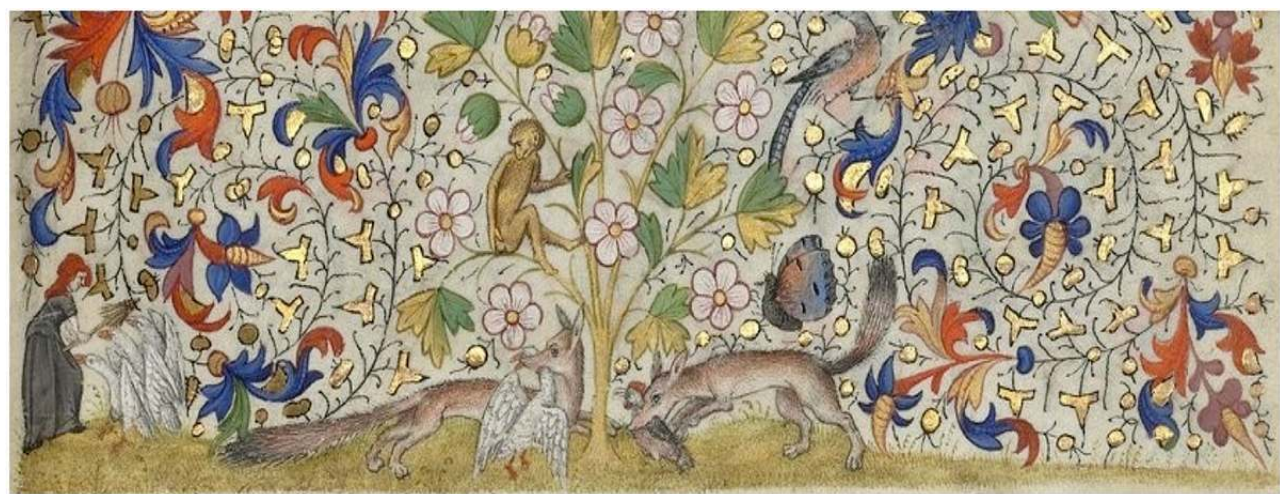

PARIS, BNF

Pour éloigner le prédateur, la fermière menace le renard avec son battoir dans des Heures flamandes du début du XVI ${ }^{\mathrm{e}}$ siècle ${ }^{127}$, plus souvent c'est avec sa quenouille qu'elle essaie de mettre en fuite l'animal, par exemple dans un Missel amiénois du XIv siècle $^{128}$. Parfois, pour aider sa compagne, le fermier brandit aussi sa fourche, comme dans un Bréviaire à l'usage de Verdun ${ }^{129}$, ou encore c'est le chien qui aboie après le rapace en train d'emporter un poussin dans ses $\operatorname{serres}^{130}$. Dans le Psautier de Gorleston, au début du XIV siècle $^{131}$, l'enlumineur va jusqu'à préciser, au-dessus de l'animal, "Queck», le cri poussé par le canard saisi par le renard.

Quand la paysanne ne surveille pas les volatiles dans leurs divagations, elle est chargée de séparer, avec sa quenouille, les volailles qui se disputent une graine ${ }^{132}$ ou les coqs qui s'affrontent, par exemple dans le Bréviaire de Marguerite de Bar ${ }^{133}$. Dans un Tacuinum lombard, c'est penchée au balcon de sa maison qu'une femme tente de déloger avec un bâton un coq dressé sur le toit du poulailler.

tâche qui devait incomber aux femmes, le nettoyage du poulailler n'est jamais évoqué par les documents iconographiques, pas plus que dans les textes médiévaux, alors que les traités antiques et modernes donnent de multiples recommandations pour maintenir ces annexes propres et hygiéniques. Par exemple Columelle ${ }^{134}$ préconise de garnir les pondoirs de paille très propre; de les nettoyer de temps en temps et de remettre « de nouvelle litière très fraîche : car ces nids se remplissent de poux et d'autre vermine, que l'oiseau y apporte avec lui chaque fois qu'il s'y rend ». Au XvI ${ }^{e}$ siècle, Olivier de Serres suggère de nettoyer les nids « puis les garnira-t-on de paille fraiche ou plutôt de foin ", mais aussi
"de nettoyer les gélines, chacune semaine une fois, sortant les fumiers de tous les endroits d'iceux, jusqu'aux juchoirs, échelettes et montées afin qu'aucune saleté n'y séjourne : de les parfumer souvent avec des herbes odorantes; $y$ faisant quelques fois brûler dedans, de l'encens, du benjoin et semblables drogues pour en chasser le mauvais air et malignes senteurs [...] $\aleph^{135}$.

C'est encore la fermière qui visite le poulailler et ramasse les œufs des poules ou des oies, en particulier dans plusieurs Tacuina sanitatis ${ }^{136}$ (Figures 3, 4 et 5). Elle grimpe parfois sur les barreaux d'une échelle pour atteindre les nichoirs les plus hauts ${ }^{137}$ et tend avec précaution les œufs à une compagne. Dans un autre manuscrit ${ }^{138}$ (Figure 9), la paysanne fait sa tournée en compagnie de sa fille. Les œufs sont ensuite soigneusement déposés dans un panier $^{139}$ (Figure 4), dans une corbeille en osier ${ }^{140}$ (Figure 9) ou dans un plat au 
pied couronne ${ }^{141}$ (Figure 3). Enfin, c'est toujours elle qui se rend au marché pour vendre $\propto \mathrm{ufs}^{142}$ et volailles ${ }^{143}$. Au sein de l'exploitation agricole, poules et «femmelettes » sont bien indissociables!

Il est vrai que si dans le cochon "Tout est bon ", cet adage pourrait également s'adapter parfaitement aux volatiles de la basse-cour et à leurs produits dérivés dont les utilisations sont multiples : de la glaire des œufs, qui entre dans la composition des couleurs pour l'enlumineur, au duvet de l'oie ou aux plumes des poules ${ }^{144}$ employés dans la literie médiévale, sans oublier les ailes utilisées pour épousseter, rien ne se perd. Surtout, volailles et œufs sont un des piliers de l'alimentation médiévale, quel que soit le milieu social. Les contrats des ouvriers agricoles attestent la distribution d'œufs lors des repas aux champs, tel ce document champenois de 1267 qui prévoit pour « Les jors que an ne mangera char, un jor un quartier de fromage, et l'autre jor quatre oes $»^{145}$. Mais les festins aristocratiques ont eux aussi largement recours aux produits de la basse-cour. Ainsi, en Savoie, pour les trois journées de banquets organisés à la cour d'Amédée VII par maître Chiquart, sont achetés "pour ung chescun jour de la dicte feste 6000 œufs » et 2000 pièces de volailles ${ }^{146}$. Ces chiffres impressionnants corroborent bien la place prépondérante de cet élevage dans l'économie du Moyen Âge.

\section{BIBLIOGRAPHIE}

Alexandre-Bidon D. 2013 - Dans l'atelier de l'apothicaire. Histoire et archéologie des pots de pharmacie $\mathrm{XIII}{ }^{e}-\mathrm{XVI}^{e}$ siècle. Paris, Picard, $336 \mathrm{p}$.

Antoine A. (Ed.) 1999 - Des animaux et des hommes. Économie et sociétés rurales en France ( $\mathrm{XI}^{\mathrm{e}}$ XIX ${ }^{\mathrm{e}}$ siècles). Annales de Bretagne 106 (1), 248 p.

Bechman R. 1984 - Des arbres et des hommes. La forêt au Moyen Âge. Paris, Flammarion, 384 p.

Borvon A. 2012 - Acquisition des ressources animales, alimentation carnée et distinction sociale en Anjou de la fin du $X^{e}$ au début du XIII siècle. Étude archéozoologique du site de Montsoreau (Maine-et-Loire). Paris, thèse dactylographiée de l'Université Paris I.

Charbonnier P. 1992 - Vivre au village à la fin du $\mathrm{XV}^{\mathrm{e}}$ siècle. In : Villages et villageois au Moyen Âge. Paris, Publications de la Sorbonne : 137-147.

Clavel B., Lepetz S., Marinval-Vigne M.-C. \& Yvinec J.-H. 1996 - Évolution de la taille et de la morphologie du coq au cours des périodes historiques en France du Nord. Ethnozootechnie 58. Le $\operatorname{coq}: 3-12$.

Colardelle M. \& Verdel É. (Ed.) 1993 - Les habitats du lac de Paladru (Isère) dans leur environnement. La formation d'un terroir au XI ${ }^{e}$ siècle. Paris, Éditions de la MSH, 416 p.

Delisle L. (1851) 1951 - Études sur la condition de la classe agricole et l'état de l'agriculture en Normandie au Moyen Âge. Évreux, Hérissey, 758 p. 
Démians d'Archimbaud G. 1980 - Les fouilles de Rougiers (Var) : contribution à l'archéologie de l'habitat rural médiéval en pays méditerranéen. Paris-Valbonne, Éditions du CNRS et Centre régional de publications de Sophia Antipolis, 774 p.

Denis B. 1998 - Évolution des méthodes d'élevage de la poule. Des agronomes de l'Antiquité à la «Maison rustique » du XIX ${ }^{\mathrm{e}}$ siècle. Ethnozootechnie 62. La poule et l'œuf : 85-112.

Ervynck A. 1993 - The Role of Birds in the Economy of Medieval and Post-Medieval Flanders: A Diversity of Interpretation Problems. Archaeofauna 2 : 107-119.

Fossier R. 1968 - La terre et les hommes en Picardie jusqu'à la fin du XIII e siècle. Paris-Louvain, Éd. Nauwelaerts, 2 vol., 828 p.

Fossier R. 1997 - L'élevage médiéval : bilan et problèmes. In : Delort R. \& Audoin-Rouzeau F. (Ed.), Ethnozootechnie 59. L'élevage médiéval : 9-20.

Franklin A. 1874 - Les rues et les cris de Paris au XIII ${ }^{e}$ siècle : pièces historiques. Paris, L. Willelm et P. Daffis, 205 p.

Gathercole P.M. 1995 - Animals in Medieval French Illumination. Lewiston, Edwin Mellen Press, $113 \mathrm{p}$.

Gaulin J.-L. 1990 - Pietro de' Crescenzi et l'agronomie en Italie (XII ${ }^{e}-X I V^{e}$ siècles). Paris, thèse dactylographiée de l'Université Paris I.

Girardot A. 1992 - Le droit et la terre. Le Verdunois à la fin du Moyen Âge. Nancy, Presses universitaires de Nancy, 2 vol., 976 p.

Grand R. \& Delatouche R. 1950 - L'agriculture au Moyen Âge de la fin de l'Empire romain au XVI e siècle. Paris, De Boccard, 740 p.

Grenouilloux A. \& Migaud P. 1993 - Sauvages, commensaux ou domestiques, l'animal dans l'économie alimentaire d'un « castrum » de l'An Mil. In : Durand R. (Ed.) L'homme, l'animal domestique et l'environnement du Moyen Âge au XVIII siècle. Nantes, Ouest Éd. : 163-176.

Guérin I. 1960 - La vie rurale en Sologne aux XIV et XV siècles. Paris, SEVPEN, 224 p.

Heck C. \& Cordonnier R. 2011 - Le bestiaire médiéval : l'animal dans les manuscrits enluminés. Paris, Citadelles \& Mazenod, 619 p.

Houbbaida M. 1987 - L'élevage dans le Sud-Ouest de la France du XII au XV siècle. Bordeaux, thèse dactylographiée de l'Université Bordeaux III.

Jouanin G. 2011 - À la table des seigneurs de Mehun. Archéologie de la fosse F 1. In : Le château et l'art à la croisée des sources, Actes du colloque de Mehun-sur-Yèvre, 23-25 novembre 2001. Mehun-surYèvre, G.H.A.M.Y : 379-386.

Kaiser-Guyot M.-T. 1974 - Le berger en France aux XIV et XV siècles. Paris, Klincksieck, 211 p.

Klingender F. 1971 - Animals in Art and Thought to the End of the Middle Ages. Cambridge (Mass.), MIT Press, 580 p.

Lacroix P. (Ed.) 1879 - Jean de Brie, Le bon berger ou Le vray régime et gouvernement des bergers et bergères. Paris, $169 \mathrm{p}$.

Luce S. 1876 - Histoire de Bertrand du Guesclin et de son époque : la jeunesse de Bertrand (1320-1364). Paris, Hachette et Cie, $624 \mathrm{p}$.

Mane P. 2004 - Images des femmes aux champs. Un regard sur l'iconographie du XIII ${ }^{\mathrm{e}}$ au XIV siècle. Enquêtes rurales, Les femmes dans les sociétés rurales 10 : 31-58. 
Mane P. 2006 - Le travail à la campagne au Moyen Âge :étude iconographique. Paris, Picard, 471 p. Monde animal (Le) 1985 - Le monde animal et ses représentations au Moyen Âge (XI ${ }^{e}-\mathrm{XV}^{e}$ siècles), Actes du XV $V^{e}$ congrès de la Société des historiens médiévistes de l'Enseignement supérieur public, Toulouse, 25-26 mai 1984. Toulouse, Université de Toulouse-Le-Mirail, Service des Publications, 190 p.

Moriceau J.-M. 2005 - Histoire et géographie de l'élevage français. Du Moyen Âge à la Révolution. Paris, Fayard, $477 \mathrm{p}$.

Nada Padrone A.M. 1981 - Il cibo del ricco ed il cibo del povero. Turin, Centro studi piemontesi, 562 p. Papin Y.D. 1993 - Le coq. Histoire, symbole, art, littérature. Paris, Hervas, 134 p.

Pastoureau M. 2011 - Bestiaires du Moyen Âge. Paris, Seuil, 235 p.

Payne A. 1990 - Medieval Beasts. Londres, The British Library, 96 p.

Petit M. 1992 - Production et techniques agricoles. In : L'T̂le-de-France de Clovis à Hugues Capet. Catalogue de l'exposition du Musée archéologique départemental du Val-d'Oise Guiry-en-Vexin et du Service régional de l'archéologie d'Île-de-France. Cergy-Pontoise, Éditions du Valhermeil : 266-271.

Pinon J.-F. 1963 - L'élevage dans la Rome antique d'après Caton, Varron, Columelle, Palladius. Toulouse, Impr. ouvrière, $82 \mathrm{p}$.

Piponnier F. 2006 - Dénominations et fonctions des espaces dans l'habitation dijonnaise ( $\mathrm{XIV}^{\mathrm{e}}-\mathrm{XV}^{\mathrm{e}}$ siècle). In : Alexandre-Bidon D., Piponnier F. \& Poisson J.-M. (Ed.), Cadre de vie et manières d'habiter (XII ${ }^{e}-\mathrm{XVI}^{e}$ siècle). Caen, Publications du CRAHM : 109-116.

Rawson J. 1977 - Animals in Art. Londres, British Museum Publications, 150 p.

Ribémont B. 1995 - De natura rerum, études sur les encyclopédies médiévales. Orléans, Paradigme, $472 \mathrm{p}$.

Yapp B. 1981 - Birds in Medieval Manuscripts. Londres, The British Library, 190 p.

\section{NOTES}

1. Cette communication doit beaucoup aux recherches communes menées par Danièle Alexandre-Bidon, Mickaël Wilmart et moi-même pour le séminaire «Recherches croisées sur la culture matérielle médiévale : de l'élevage au produit » qui s'est tenu durant l'année universitaire 2013-2014, à l'EHESS, ainsi qu'aux enquêtes effectuées dans le cadre de ma thèse d'État (Mane 2006 :378-386).

2. D'autres noms renvoient à une ressemblance avec l'oie ou la poule : Bec d'Oë, Piz d'Oë, Col d'Oë et Vit-de-Coq (Franklin 1874: 62 et 67).

3. Mc XIV, 72 : «Et Pierre se souvint de la parole que Jésus lui avait dite : avant que le coq chante deux fois, tu me renieras trois fois ».

4. Notamment au début $\mathrm{du} \mathrm{IX}^{\mathrm{e}}$ siècle, l'Évangéliaire de Saint-Médard de Soissons (Paris, BnF, Latin 8850, f. 2v), mais aussi la Bible de Vivien de Charles Le Chauve (Paris, BnF, Latin 1, f. 326) ou la Bible de Théodulphe (Paris, BnF, Latin 9380, f. 48v), et plus tardivement l'Évangéliaire de Blois (Paris, BnF, Latin 265, f. 8v), enluminé à Reims durant la première moitié du $\mathrm{X}^{\mathrm{e}}$ siècle.

5. Londres, British Library (BL), Add. 42130, f. 31, 166v ou 169v, Add. 50000, f. 156v, Add. 49622, f. 190v, ou Oxford, Bodleian, Douce 131, f. 42v, Douce 118, f. 7v et Douce 366, f. 71v, Baltimore, Walters Art Gall., ms. 102, f. 77v, etc.

6. Verdun, BM, ms. 107, f. 57, Paris, BnF, Latin 1029 A, f. 45v ou Londres, BL, Yates Thompson 8, f. 335 . 
7. Notamment dans les Heures de Marguerite d'Orléans: Paris, BnF, Latin $1156 \mathrm{~B}, \mathrm{f} .133$. Dans l'iconographie médiévale, cet animal est, il est vrai, le symbole de l'hypocrisie, du vol et de la tricherie. Voir par exemple Pastoureau $2011: 130-131$.

8. Également dans la marge de plusieurs manuscrits, tels les Décrétales de Smithfields de Grégoire IX (Londres, BL, Royal 10 E IV, f. 49v) ou le Missel de Jean de Foix (Paris, BnF, Latin 16827, f. 19 ou 85). À l'inverse, c'est le coq qui prêche au renard dans le Psautier d'Oscott (Londres, BL, Add. 50000, f. 156v).

9. Glasgow, Burrell Coll., Reg 46/38.

10. Londres, BL, Add. 29433, f. 59.

11. Par exemple Paris, BnF, Français 1877, f. 16. Le texte précise : « On peut s'approprier la vertu de notre réjouissance au coq. Lequel de joie et de réjouissance chante selon les heures par mouvement de jouissance naturelle de son cœur ».

12. Cet ouvrage est composé de cent courts récits empruntés à la mythologie et à l'histoire antiques, destinés à susciter la réflexion : cf. Londres, BL, Harley 4431, f. 115v, Paris, BnF, Français 606, f. 21v, ou encore Waddesdon, coll. J. A. Rothschild, ms. 8, f. 28, etc.

13. Dixième nouvelle du livre 5 : par exemple Paris, Arsenal, ms. 5070, f. 215v, ou Vatican, Bibl. Apostolique, Vat. Lat. 1989, f. 177v.

14. Comme dans un exemplaire des Fables d'Ésope produit à Venise durant le troisième quart du $\mathrm{XIII}^{\mathrm{e}}$ siècle (Paris, BnF, Français 2173, f. 93) ou à la fin du $\mathrm{XV}^{\mathrm{e}}$ siècle à Florence (New York, Public Libr., Spencer 50, f. 7v).

15. Par exemple Paris, BnF, Nal 3134, f. 22.

16. Par exemple en janvier : Bruxelles, Bibl. Royale, ms. II. 158, f. 1 ou Munich, Bay. Staat. Bibl., Clm 23638, f. 2v, en février: La Haye, museum Meermanno, ms. 133 D 11, f. 3 et Venise, Bibl. Marciana, Lat I. 99, f. 2v, en avril : Anvers, musée Mayer Van den Bergh, ms. 946, f. 3 ou Londres, BL, Add. 35313, f. 4, en novembre : Londres, BL, Add. 24098, f. 28v, Vienne, ÖNB, ms. 2706, f. 6 , New York, Pierpont Morgan Libr., ms. 399, etc.

17. Voir par exemple la rubrique Gallus du Bestiaire Ashmole, enluminé vers 1200 dans le nord des Midlands (Oxford, Bodleian, Ashmole 1511, f. 10) ou au XIII ${ }^{\mathrm{e}}$ siècle, dans des exemplaires produits dans le nord de la France (Chalon-sur-Saône, BM, ms. 14, f. 56, Valenciennes, BM, ms. 101, f. 179).

18. Ce bestiaire donne une interprétation symbolique des oiseaux mentionnés dans la Bible ou dans les écrits patristiques. Voir par exemple l'exemplaire enluminé durant le dernier quart du $\mathrm{XII}^{\mathrm{e}}$ siècle (Troyes, BM, ms. 177, f. 146v).

19. Pourtant dans son texte, Barthélemy l'Anglais, à part quelques remarques sur le chant du coq, ne considère pas ces volatiles de basse-cour en tant qu'animaux domestiques, mais, comme la majorité des encyclopédistes, sauf Brunet Latin, dans une perspective pharmacologique, au même titre que les plantes. Ils sont donc traités hors de leur milieu et de leur relation à l'homme (Ribémont 1995 : 426-427).

20. Varron (De agricultura, Livre III, 3) propose d'élever dans la volière, les paons, les tourterelles, et les grives, d'une part, d'autre part les espèces à qui il faut «la terre et l'eau »: les oies, les sarcelles, les canards.

21. Livre IX. Nous retrouvons une moindre diversité chez Brunet Latin (Livre du trésor, Livre I, CLXXX), mais sa description s'adresse sans doute à un milieu social moins aristocratique: "Comment hom doit garnir sa maison et de queles choses : Quant ta maison est complie et garnie de ses edefiemenz selonc l'estat dou leu et dou tens, tu doiz faire chambres et cheminées là où li chans de ta maison te mosterra que miex soit ; et si penseras de molin et de four et de vivier et de columier et de estable à berbiz et à prociaus, et de gelines, et de chapons, et d'oies, et d'anetes [... ]".

22. Par exemple Bruxelles, Bibl. Royale, ms. 6, f. 9, Londres, BL, Add. 38126, f. 145v, Harley 4425, f. 19v, Munich, Bay. Staat. Bibl., Clm 23638, f. 5v, Oxford, Bodleian, Laud. Misc. 751, f. 19v, Paris, BnF, Français 59, f. A, etc. 
23. Comme dans Vienne, ÖNB, ms. 2706, f. 6, ou Saint-Pétersbourg, Bibl. Nationale Russe, Fr. F. V. XIV, 8, f. 31v.

24. Selon M. Petit (1992 : 266-271), en Île-de-France durant le haut Moyen Âge, à « l'exception de quelques rares "chapons" (coqs châtrés et engraissés), ces espèces sont en général d'assez petite taille et chaque individu ne représentait donc qu'un faible poids en viande ». De même, à Paladru, le haut Moyen Âge voit revenir des volailles de taille réduite rappelant celles de la période Hallstatt-La Tène (Colardelle \& Verdel 1993 : 109).

25. Ces tailles modestes se retrouvent d'ailleurs alors pour l'ensemble des espèces animales élevées.

26. Naturalis historia, Livre X, LXXVII (LVI). Ou encore Columelle (De re rustica, Livre VIII, II, 14) qui n'en fait pas grand cas: les «volailles naines, qui ne peuvent plaire qu'en raison de leur petitesse, car elles ne sont recommandables ni pour la fécondité, ni pour les bénéfices qu'on doit en attendre ".

27. Livre des profits champêtres et ruraux, IX, VII. Reprenant Columelle (De re rustica, Livre VIII, II, 7) : « Le plumage [des poules] doit être ou rouge ou brun, et leurs ailes noires : s'il est possible, on les choisira toutes de cette même couleur, ou du moins d'une nuance qui en approche » et à sa suite Palladius, à la fin du IV siècle apr. J.-C., dans son De re rustica (Livre I, XXVII) : « Préférez les noires et les rousses $»$.

28. Paris, BnF, Latin 265, f. 8v.

29. Sienne, Bibl. Com., ms. X. IV. 2, f. 6.

30. Vienne, ÖNB, Sn 2644, f. $65 \mathrm{v}$, ou Rome, Casanatense, ms. 459, f. $115 \mathrm{v}$.

31. Paris, BnF, Latin 1156 B, f. 31.

32. Paris, BnF, Français 22531, f. 190v.

33. Paris, BnF, Nal 1673, f. 60.

34. New York, Public Libr., Spencer 50, f. 8.

35. Waddesdon, Coll. J. A. Rothschild, ms. 8, f. 28, comme dans un autre manuscrit du Xve siècle : New York, Public Libr., Spencer 50, f. 7v.

36. Livre VIII, 7.

37. Livre du trésor, Livre I, CLXXV.

38. Par exemple Paris, BnF, Latin 5971 A ou Londres, College of Arms, Vincent ms. 152, f. 77.

39. Lisbonne, BN, ms. II. 72, f. 442.

40. Oxford, Bodleian, Douce 366, f. 71v.

41. Paris, BnF, Français 22971, f. 25.

42. Livre des profits champêtres et ruraux, IX, VII.

43. Anvers, musée Mayer Van den Bergh, ms. 946, f. 3.

44. Paris, BnF, Français 9140, f. 211.

45. Cf. Le Livre du trésor, Livre I, CLXXV : « Coc est uns oisiaus domesches qui maint entre les homes tozjors, et par sa voiz monstre les eures du jour et de la nuit et les muemens dou tens, jà soit ce que de nuit il chante plus haut et plus orguilleusement, mais vers le jor il chante plus cler et plus soef ; mais il bat son cors et ses eles, avant que il chante III foiz. »

46. Livre des profits champêtres et ruraux, IX, VII.

47. Liège, Bibl. Univ., ms. 1041, f. 54.

48. Vienne, ÖNB, Sn 2644, f. 65.

49. Rares sont les constructions en dur attestées par les fouilles archéologiques ; voir notamment à Rougiers (Démians d'Archimbaud $1980: 410$ ).

50. Berne, Burgerbibl., ms. 318, f. 21. Il est pourtant aventureux d'affirmer que cette enluminure figure un bâtiment en dur spécifiquement réservé aux poules et surtout qu'il était voûté en raison de la perspective encore mal maîtrisée par les artistes du IX ${ }^{\mathrm{e}}$ siècle.

51. Paris, BnF, Français 1580, f. 20. 
52. Théâtre d'agriculture, Livre V, chapitre 1 : Leur capacité et chapitre 2 : Façon du logis de la poulaille commune.

53. Paris, BnF, Nal 1673, f. 60.

54. Varron (De agricultura, Livre III, 9) préconise d'installer les poules dans « un lieu clos, dans lequel on dispose deux cabanes l'une à côté de l'autre, toutes deux au soleil levant» comme Columelle (De re rustica, Livre VIII, III, 1) : « Les poulaillers doivent être établis dans la partie de la ferme qui est tournée vers l'Orient d'hiver ».

55. Théâtre d'agriculture, Livre $\mathrm{V}$, chapitre 1 : De la disposition des poulaillers.

56. Vienne, ÖNB, Sn 2644, f. $65 \mathrm{v}$ et collection privée, f. 64 . Mais également dans un exemplaire rhénan : Paris, BnF, Latin 9333, f. 63v.

57. Venise, Marciana, Lat I. 99, f. 2v, Londres, BL, Add. 24098, f. 18v ou Bruxelles, Bibl. Royale, ms. II. 158, f. 1, Munich, Bay. Staat. Bibl., Clm 23638, f. 2 v.

58. Déjà Columelle (De re rustica, Livre VIII, III, 6) précise qu'à l'extérieur du poulailler « du côté de la cour, on fixera aussi, au-dessous des fenêtres dont nous avons parlé, de petites échelles par lesquelles les volailles iront chercher le repos de la nuit». Quant à Olivier de Serres (Théâtre d'agriculture, Livre V, chapitre 2: Façon du logis de la poulaille commune) : «L'autre ouverture servira d'entrée [...] on y accommodera au-devant une échellette portant de petits degrés, par laquelle la poulaille se rendra aisément dans le gélinier. "

59. Londres, BL, Add. 24098, f. 18v ou Munich, Bay. Staat. Bibl., Clm 23638, f. 2v.

60. Anvers, musée Mayer Van den Bergh, ms. 946, f. 3.

61. AN : JJ 119, n² 232, f. 145. Cf. Luce 1876 : 8-9.

62. Théâtre d'agriculture, Livre V, chapitre 1 : De la disposition des poulaillers. De même, en 1554, Charles Estienne et Jean Liébault dans l'Agriculture et Maison rustique (Livre I, chapitre 15) conseillent de placer le poulailler loin du logis du maître, mais plutôt près du four "afin que la chaleur aide à pondre aux gélines, et la fumée qui est fort saine à la poulaille vienne jusque-là ».

63. Livre des profits champêtres et ruraux, IX, VII, et Gaulin $1990: 331$.

64. Théâtre d'agriculture, Livre $\mathrm{V}$, chapitre 2 : Façon du logis de la poulaille commune. Déjà Columelle (De re rustica, Livre VIII, III, 6) recommande que les poulaillers «soient, à l'intérieur comme à l'extérieur, revêtus d'un enduit bien poli, afin que les fouines ou les couleuvres n'y puissent gravir, et qu'ils n'aient rien à redouter d'aucun animal nuisible ».

65. Vienne, ÖNB, Sn 2644, f. 65.

66. Paris, BnF, Latin 9333, f. 63.

67. Vatican, Bibl. Apostolique, Vat. Lat. 1989, f. 177v.

68. Paris, Arsenal, ms. 5070, f. 215v.

69. Par exemple Vienne, ÖNB, Sn 2644, f. 65v, Liège, Bibl. Univ, ms. 1041, f. 54 et 81v.

70. Liège, Bibl. Univ., ms. 1041, f. 81v.

71. Pourtant en 1572, Prudent Le Choyselat, dans son Discours oeconomique (p. 12) explique que les morceaux de bois doivent être carrés : « que les montouers soient plats et non pas ronds, parce que la poulle ne courbe les ongles comme les autres oyseaux qui agrappent leurs montouers ». Voir dans ce même volume, l'article de Mickaël Wilmart.

72. Liège, Bibl. Univ., ms. 1041, f. 54.

73. Londres, BL, Harley 4431, f. 115v.

74. Déjà Varron, dans son De agricultura (Livre III, 9), conseille d'installer des nids tout autour du poulailler, «creusés ou attachés fortement aux murs ». Il sera repris par Columelle (De re rustica, Livre VIII, III, 4) qui juge cette « disposition plus saine et plus élégante que celle qui est adoptée par certaines personnes, et qui consiste à établir des paniers d'osier sur des pieux solidement fixés dans la muraille ».

75. Rome, Casanatense, ms. 459. Ce type d'aménagement se retrouve pour les oies dans plusieurs Tacuina : Vienne, ÖNB, Sn 2644, f. 66 ou collection privée (f. 74). 
76. La corbeille ne dépasse pas $5 \mathrm{~cm}$ de haut dans les Heures de la Duchesse de Bourgogne (Chantilly, Condé, ms. 76, f. 3v), comme dans un Tacuinum lombard où le pondoir est alors destiné aux oies (Paris, BnF, Nal 1673, f. 61).

77. Liège, Bibl. Univ., ms. 1041, f. 41v.

78. Liège, Bibl. Univ., ms. 1041, f. 41v. Dans ce poulailler, les niches côtoient un panier à pondre posé directement sur le sol.

79. $\mathrm{Au} \mathrm{XVI}{ }^{\mathrm{e}}$ siècle, Olivier de Serres (Théâtre d'agriculture, Livre V, chapitre 2 : Ses nids) préconise cet aménagement qu'il dénomme aix (petite planche en français médiéval) : « afin que de celui-ci les poules puissent commodément entrer dans leurs nids, sans contrainte d'y voler dedans, en danger d'y casser les œufs y étant ", mais également d' « empêcher les œufs de verser dehors au remuement des poules ». L'agronome précise encore que les "meilleurs nids sont ceux qu'on façonne dans l'épaisseur de la muraille, garnis en bas et sur les côtés de quelques petits aix, qui se puissent ôter et remettre pour la netteté, y en ajoutant un de quatre doigts de large par le devant : afin de retenir les œufs de couler en dehors, en lui servant de barrière ». Mais Columelle, dans son De re rustica, conseillait déjà de faire précéder ces nichoirs « d'un vestibule par lequel les poules puissent y parvenir, tant pour pondre que pour couver: car il ne faut pas qu'elles y arrivent en volant, de peur qu'en se jetant ainsi sur les œufs, elles ne les cassent avec leurs pattes $»$.

80. Selon Varron, une poule peut couver vingt-cinq œufs (De agricultura, Livre III, 9) : «On prétend qu'il ne faut pas donner à une poule plus de vingt-cinq œufs à couver, lors même qu'elle est assez féconde pour en pondre davantage ». Cette estimation est reprise par Pline l'Ancien ( Naturalis historia, Livre X, LXXIV (LIII)) : « On défend de donner à une poule plus de vingt-cinq œufs à couver. » Plus curieusement Columelle (De re rustica, Livre VIII, V, 8) observe qu'il ne faut « donner à couver qu'un nombre d'œufs qui soit impair et variable selon les époques : ainsi dans le premier temps, c'est-à-dire au mois de janvier, on en mettra quinze sous la poule et jamais plus ; au mois de mars, dix-neuf et jamais moins ; vingt et un au mois d'avril, et autant pendant tout l'été, jusqu'aux calendes d'octobre. Plus tard, il n'y a plus à s'occuper de ce soin, parce que les poussins qui éclosent pendant le froid meurent ordinairement ».

81. Livre des profits champêtres et ruraux, IX, VII.

82. Columelle (De re rustica, Livre VIII, V, 15) précise que: «On ne doit pas enlever chaque poussin dès qu'il est né, mais le laisser durant un jour dans le nid, sous sa mère. »; le lendemain, " on les renferme avec leur mère dans une cage. On les y retient trois jours. ». Ces propos sont repris au $\mathrm{XVI}^{\mathrm{e}}$ siècle par Olivier de Serres (Théâtre d'agriculture, Livre $\mathrm{V}$, chapitre 2 : Premier soin des poussins) : «Ne se faut hâter de retirer les poussins à mesure qu'ils naissent et convient de les laisser sous la mère un jour et davantage [...]».

83. Cette période doit durer quarante jours selon Columelle (De re rustica, Livre VIII, V, 19) et, au $\mathrm{XVI}^{\mathrm{e}}$ siècle, Olivier de Serres parle de cinq à six semaines.

84. Vienne, ÖNB, ms. 2706, f. 6.

85. La mue a pourtant pour inconvénient de ne pas abriter la poule et ses poussins de la pluie, du vent et du soleil.

86. Livre des profits champêtres et ruraux, IX, VII.

87. Paris, BnF, Latin 1, f. 326.

88. Leyde, Bibl. Univ., Voss Lat Oct 15.

89. Londres, BL, Add. 42130, f. $166 \mathrm{v}$.

90. De re rustica, livre VIII, IV, 1.

91. Également conseillée par Palladius (De re rustica, Livre I, XXVII).

92. En revanche cet aliment est totalement à proscrire en période de ponte car les œufs seraient moins nombreux et plus petits.

93. Théâtre d'agriculture, Livre V, chapitre $2:$ La pasture de la volaille.

94. Livre du trésor, Livre I, CLXXV : Dou Coc. 
95. Liège, Bibl. Univ., ms. 1041, f. 31. C'est près d'un tas de blé attendant d'être vanné que les poules picorent dans l'enluminure bourbonnaise du début $d u \mathrm{XVI}^{\mathrm{e}}$ siècle illustrant Cérès dans une Recueil de poèmes et dessins pour tapisseries (Paris, Arsenal, ms. 5066, f. 25).

96. Columelle, De re rustica, Livre VIII, V, 23.

97. Olivier de Serres, Théâtre d'agriculture, Livre V, chapitre 2 : L'abreuvoir de la poulaille.

98. Lisbonne, BN, ms. Il. 72, f. 442.

99. Bruxelles, Bibl. Royale, ms. II. 158, f. 1, La Haye, Museum Meermanno, ms. 133 D 11, f. 3, Londres, BL, Add. 35313, f. 4, Munich, Bay. Staat. Bibl, Clm 23638, f. 2v, Venise, Bibl. Marciana, Lat I. 99, f. 2v, Waddesdon, Coll. J. A. Rothschild, ms. 26, f. 6v-7, Paris, BnF, Français 606, f. 21v...

100. Anvers, musée Mayer Van den Bergh, ms. 946, f. 3 ou Vienne, ÖNB, ms. 2706, f. 6.

101. New York, Pierpont Morgan Libr., ms. 399, f. 11, Vienne, ÖNB, ms. 2706, f. 16, Londres, BL, Add. 24098, f. 28v.

102. Sienne, Bibl. Com., ms. X. IV. 2, f. 6.

103. Florence, BN, Pal 586, f. 9.

104. Voir par exemple la poule dressée sur un perchoir à côté de la cheminée dans des Prières pour la semaine sainte enluminées au $\mathrm{XV}^{\mathrm{e}}$ siècle (Londres, collection P. R. Robinson, f. 18v) ou, au début du siècle suivant, le retable de la Passion (basilique Sainte-Marie-Madeleine de SaintMaximin-de-la-Sainte-Beaume) où une poule est juchée sur une poutre. Cf. Charbonnier 1992 : 137-147. Comme l'indiquent également plusieurs miracles du XII siècle et des exempla du XIII ${ }^{\mathrm{e}}$ siècle (cf. dans ce même volume l'article de Marie Anne Polo de Beaulieu).

105. Par exemple Vienne, ÖNB, ms. 2706, f. 6, ou Sienne, Bibl. Com., ms. X. IV. 2, f. 6.

106. Londres, BL, Add. 42130, f. 19.

107. Stuttgart, Württ. Landesbibl., Folio 23, f. 62v. Ces troupeaux mixtes, comprenant cette fois bovins et poules, se retrouvent au $\mathrm{XV}^{\mathrm{e}}$ siècle, dans des Chroniques de Hainaut de Jacques de Guise (Paris, BnF, Français 20127, f. 66).

108. Waddesdon, Coll. J. A. Rothschild, ms. 26, f. 6v-7.

109. Déjà Palladius (De re rustica, Livre I, XXX : Des oies) notait que ce volatile était « le fléau des lieux ensemencés, auxquels sa fiente ne nuit pas moins que son bec ».

110. De même, dans le Verdunois, de nombreuses amendes sanctionnent la divagation des oies, en particulier à Rouvres et à Pareid en 1390, à Souilly en 1399, à Neuvilly en 1470 (Girardot 1992 vol. $1: 222$ ).

111. AD. Gironde T. 15, art. 189, p. 151, cité par Houbbaida $1987: 256$.

112. Jean de Brie «fut lors institué et député à garder les oues et les oysons audit lieu de Villiers, lesquelz il garda bien et loyaument en son povoir par l'espace de demy an au plus, en deffendant iceulx oues et oysons des escoufles, des huas, des pies, des corneilles, et d'aultres choses à eux contraires ou nuysibles » (éd. Lacroix $1879: 15-16$ ).

113. Venise, Bibl. Marciana, Lat I. 99 , f. 8.

114. Paris, Sainte-Geneviève, édition de 1517. Quant au pâtre du Psautier de Luttrell, il éloigne l'oiseau qui menace les oies avec son chaperon et une crosse identique à celle des gardiens d'ovins (Londres, BL, Add. 42130, f. 169v).

115. Paris, BnF, Latin 16827, f. 3.

116. Paris, BnF, Latin 1156 B, f. 133.

117. Saint-Pétersbourg, musée de l'Ermitage. Mais également sur le décor d'un albarello du début $\mathrm{du} \mathrm{XVI}^{\mathrm{e}}$ siècle, provenant de Deruta ou de Montelupo (Los Angeles, J. P. Getty Museum, inv. 84 DE 112.2, cf. Alexandre-Bidon 2013 : 257).

118. Livre I, XXVII. Pour Columelle (De re rustica, Livre VIII, II, 7) : " Le nombre de poules à se procurer est de deux cents : une seule personne suffira pour les soigner, pourvu qu'on lui associe soit une vieille femme, soit un enfant, qui veillent à ce qu'elles ne s'écartent pas, afin qu'elles ne deviennent pas la proie, ou des voleurs qui leur tendent des pièges, ou des animaux ravisseurs. » 
119. Livre 5, chapitre 1: La gouvernance de la volaille. «La mère-de-famille pour son soulagement, commettra au gouvernement de sa poulaille, la plus experte et diligente de ses servantes, se réservant toutefois la principale intelligence de ce négoce. Laquelle servante par charge expresse, aura le soin de nourrir la poulaille, l'enfermer, l'ouvrir et souvent recognoistre." "

120. Londres, BL, Add. 42130, f. 166v.

121. Paris, BnF, Latin 9333, f. 63, ou Vienne, ÖNB, Sn 2644, f. 65 et ms. 2396, f. 24.

122. Liège, Bibl. Univ., ms. 1041, f. 54.

123. Aussi bien dans la sculpture, par exemple sur la frise de la façade de Saint-Pierre et SaintPaul d'Andlau, dès la première moitié $d u$ XIII ${ }^{\mathrm{e}}$ siècle, comme dans les enluminures, au XIII ${ }^{\mathrm{e}}$ ou au $\mathrm{XV}^{\mathrm{e}}$ siècle : Bruges, Grand Séminaire, ms. 4/1, Oxford, Bodleian, Douce 366, f. 71v ou Ashmole 1504, f. 33v, aussi Londres, BL, Stowe 17, f. 10 ou Harley 6563, f. 60v, Madrid, BN, B. 31, f. 197, Chantilly, Condé, ms. 1389 (680), f. 49, Paris, BnF, Latin 1156 B, f. 133...

124. Lisbonne, BN, ms. Il. 72, f. 442.

125. Paris, BnF, Français 1877, f. 14. De même les miséricordes, par exemple celle de la cathédrale de Saint-Jean-de-Maurienne où le renard tient une poule dans sa gueule.

126. Paris, Arsenal, ms. 5196, f. 370.

127. Baltimore, Walters Art Gallery, ms. 88, f. 155.

128. La Haye, Museum Meermanno, ms. 78 D 40, f. 31 ou encore Londres, BL, Add. 49622, f. 190v, Royal 10 E IV, f. 49v, Stowe 17, f. 4v, Oxford, Bodleian, Douce 366, f. 71v, Ashmole 1504, f. 33v et Vatican, Bibl. Apostolique, Urb Lat 603, f. 41v.

129. Verdun, BM, ms. 107, f. 57.

130. Lisbonne, BN, ms. Il. 72, f. 442.

131. Londres, BL, Add. 49622, f. 190v.

132. Oxford, Bodleian, Douce 118, f. $7 \mathrm{v}$.

133. Londres, BL, Yates Thompson 8, f. 335, enluminé en Lorraine vers 1302-1304.

134. De re rustica, Livre VIII, 3.

135. Théâtre d'agriculture, Livre V, chapitre 2 : La gouvernance de la poulaille, repris en 1612 par Prudent Le Choyselat dans son Discours oeconomique..., 19-20: «Et le matin d'ouvrir les entrées et fenestres, pour donner yssue aux poulles : après qu'elles seront sorties nettoyer et decrotter les montouers [...] il convient de rafreschir [le foin] : ce qu'elles doivent faire par chacune semaine, pour crainte d'un engendrement de poux, pusserons et vermines, qui emmaigrissent les poulles et leur causent la gratelle. »

136. Rome, Casanatense, ms. 459, Paris, BnF, Latin 9333, f. 63 et 63v, Nal 1673, f. 60 et 61, Vienne, ÖNB, Sn 2644, f. $65 \mathrm{v}$ et 66 .

137. Paris, BnF, Nal 1673, f. 60.

138. Liège, Bibl. Univ., ms. 1041, f. $41 \mathrm{v}$.

139. Paris, BnF, Latin 9333, f. $63 \mathrm{v}$ ou 64.

140. Liège, Bibl. Univ., ms. 1041, f. $41 \mathrm{v}$.

141. Paris, BnF, Nal 1673, f. 60.

142. Bruxelles, Bibl. Royale, ms. 1175, f. 59.

143. Paris, BnF, Français 12559, f. 167, Nal 1673, f. 65, ou Latin 9333, f. 65.

144. Pour Hildegarde de Bingen, Livre des subtilités des créatures divines, Livre des oiseaux, chapitre XIV : «Les plumes de la poule sont mauvaises pour faire les oreillers parce qu'elles provoquent la goutte chez l'homme qui repose dessus. "

145. Campan. fol.273. col.2. Cf. Du Cange et al., Glossarium mediae et infimae latinitatis. Niort, L. Favre, 1883-1887, t. 6, col. 81b. http://ducange.enc.sorbonne.fr/OVUM1

146. Toujours chez Chiquart, pour la seule recette de la soupe jacobine, il «fault que haies voz beaulx chappons et, selon la quantité de la feste, cent ou IIC chappons de haulte gresse, et d'aultre poullaille a grant foyson pour servir » (recette 18). 


\section{RÉSUMÉS}

Dans l'iconographie médiévale, nombreux et variés sont les documents qui figurent poules et poulaillers. Comparés aux vestiges archéologiques ou aux sources écrites, en particulier la littérature agronomique contemporaine, ils soulignent l'importance de la volaille et des œufs dans le régime alimentaire de la population et attestent le rôle non négligeable tenu par les gallinacés non seulement dans la vie des campagnes mais aussi dans une économie urbaine en pleine croissance.

In the medieval iconography, the documents which represent hens and henhouses are many and varied. They underline the importance of the poultry and of the eggs in the food balance of the population and give evidence of the significant role held by gallinaceans not only in the life of rural areas but also in the urban economy which is rapidly expanding.

\section{INDEX}

Mots-clés : iconographie, poulailler, élevage, basse-cour, travail féminin, économie

Keywords : iconography, henhouse, breeding, farmyard, feminine work, economy

\section{AUTEUR}

\section{PERRINE MANE}

Directrice de recherches GAM, CRH/CNRS

54 boulevard Raspail 75006 Paris

mane@ehess.fr 